\title{
Narraciones andinas coloniales. Oralidad y visualidad en los Andes
}

Narrations orales et visuelles dans les Andes coloniales

Colonial Andean narratives. Orality and visuality in the Andes

José Luis Martínez C. y Paula Martínez S.

\section{CpenEdition}

\section{Journals}

Edición electrónica

URL: https://journals.openedition.org/jsa/12858

DOI: $10.4000 /$ jsa. 12858

ISSN: $1957-7842$

Editor

Société des américanistes

Edición impresa

Fecha de publicación: 30 diciembre 2013

Paginación: 41-81

ISSN: 0037-9174

Referencia electrónica

José Luis Martínez C. y Paula Martínez S., «Narraciones andinas coloniales. Oralidad y visualidad en los Andes», Journal de la Société des américanistes [En línea], 99-2 | 2013, Publicado el 01 enero 2016, consultado el 02 septiembre 2022. URL: http://journals.openedition.org/jsa/12858 ; DOl: https:// doi.org/10.4000/jsa. 12858 


\title{
NARRACIONES ANDINAS COLONIALES. ORALIDAD Y VISUALIDAD EN LOS ANDES
}

\author{
José Luis MARTÍNEZ C. y Paula MARTÍNEZ S. *
}

\begin{abstract}
Durante el período colonial (siglos XVI-XVIII), continuaron circulando diversos textos, tanto visuales como orales, producidos o registrados por los pobladores andinos. Entre ellos destacan los queros o vasos de madera usados para beber chicha en contextos rituales y de reciprocidad, y los fragmentos de textos orales recogidos en obras como la de Huarochirí o aquellas de Guaman Poma de Ayala y Pachacuti Yamqui. En este trabajo se propone que existía una estrecha relación semiótica entre, por una parte, las narraciones orales y escritas y, por otra parte, aquellas que se pueden identificar en las escenas que decoraban los queros coloniales. La propuesta permite avanzar en el proceso de comprensión respecto del funcionamiento de los lenguajes visuales y orales andinos de aquel tiempo, ampliando el corpus de fuentes que pueden ser usadas para lograr un mejor conocimiento de las voces andinas de ese período. [Palabras claves: Andes, queros coloniales, oralidades, narraciones, Colonia, etnohistoria.]
\end{abstract}

Narrations orales et visuelles dans les Andes coloniales. Pendant la période coloniale (XVI ${ }^{\mathrm{e}}$-XVIII ${ }^{\mathrm{e}}$ siècles), quelques textes aussi bien graphiques qu'oraux émanant des populations andines ont continué à circuler. C'est particulièrement le cas des queros, gobelets en bois utilisés pour boire de la chicha lors des rituels de réciprocité, et des fragments de textes oraux recueillis dans des ouvrages tels que le récit de Huarochirí ou les chroniques de Guaman Poma de Ayala et Pachacuti Yamqui. On propose ici l'existence d'une étroite liaison sémiotique entre, d'une part, les textes oraux et écrits et, d'autre part, ce qui peut être identifié dans les scènes peintes sur les queros coloniaux. Tout en amplifiant le corpus de sources mobilisables sur cette époque, on parvient ainsi à une meilleure compréhension du fonctionnement des langages andins de la période coloniale [Mots-clés: Andes, queros coloniaux, récits oraux, narrations, période coloniale, ethnohistoire.]

Colonial Andean narratives. Orality and visuality in the Andes. During the colonial period (16th-18th centuries), various visual and oral texts, produced or registered by Andean people, continued to circulate. Among them, stand out the queros or wooden

* Universidad de Chile, Facultad de Filosofía y Humanidades, Centro de Estudios Culturales Latinoamericanos [jomarcer@u.uchile.cl]. Universidad Autónoma de Chile [pmartinezsagredo@, gmail.com].

Journal de la Société des Américanistes, 2013, 99-2, pp. 41-81. (C) Société des Américanistes. 
cups used for drinking chicha in ritual contexts of reciprocity, and the fragments of oral texts collected in works like that of Huarochirí or those of Guaman Poma de Ayala and Pachacuti Yamqui. This paper argues that there was a close connection between the semiotics of oral and written narratives and those that can be identified in the scenes that decorated the colonial queros. This provides a better understanding of the visual and oral Andean language of that period, expanding the corpus of sources that can be used to achieve a better knowledge of the Andean voices of that period. [Key words: Andes, colonial queros, oral discourses, narrations, Colonial times, etnohistory.]

En este trabajo nos proponemos comparar algunas estructuras narrativas que hemos encontrado en textos andinos, ya sean escritos o visuales. Nuestra propuesta consiste en que tanto en unos como en otros es posible identificar una práctica oral subyacente, que hace que estos distintos textos compartan determinados procedimientos de construcción narrativa similares. Por textos andinos escritos entendemos aquellos que son producto o bien de la autoría de un escritor de origen andino, por ejemplo, Felipe Guaman Poma de Ayala (2004 [1616]), o Joan de Santa Cruz Pachacuti Yamqui Salcamaygua (1993 [1613?]), o bien de una situación comunicativa dentro de la cual un informante andino puede ser considerado como fuente principal (el Manuscrito de Huarochirí, Taylor 1987), o aun son fragmentos orales rescatados por algún recopilador, como los que se encuentran en la Relación de Cristóbal de Molina (2010 [1575]), o en el Rituale seu manuale peruanum, de Jerónimo de Oré (1607), y otros. Consideramos, así, como textos orales aquellos que nos han llegado a través de la tradición escrituraria, cuyo origen puede ser asignado - en virtud de las informaciones que podemos obtener gracias al método filológico - a una instancia comunicativa de carácter oral, como los fragmentos rescatados por Taylor (2003) de las pláticas evangelizadoras. Vamos a considerar como textos de origen oral aquellos que conservan las marcas de oralidad como fueron expuestos en Martínez S. (2010), entre los que destacan aquellos que fueron registrados en una instancia de comunicación oral, otros que emulan una situación de oralidad y otros que tienen marcas gráficas de haber sido de origen oral (por ejemplo, el Manuscrito de Huarochirí). Para esta comparación nos centraremos, sin embargo, en aquellos textos más canónicos según la crítica lingüístico-filológica ${ }^{1}$ (Guaman Poma de Ayala, el Manuscrito de Huarochirí y Pachacuti Yamqui Salcamaygua).

Los queros coloniales (Figura 1) ${ }^{2}$, por su parte, son aún poco conocidos por la mayoría de los estudiosos de la sociedad andina colonial ${ }^{3}$. Sin embargo fueron símbolos de prestigio para muchas autoridades indígenas coloniales (Del Río 2010), así como concitaron el interés de algunos funcionarios europeos. En efecto, a lo largo del período colonial fueron varios los altos funcionarios de la Corona que, atraídos por la belleza y la singularidad de los queros coloniales, enviaron algunos ejemplares como regalos a los reyes de España ${ }^{4}$. Las superficies de estos vasos de madera, primero talladas y posteriormente rellenadas con 


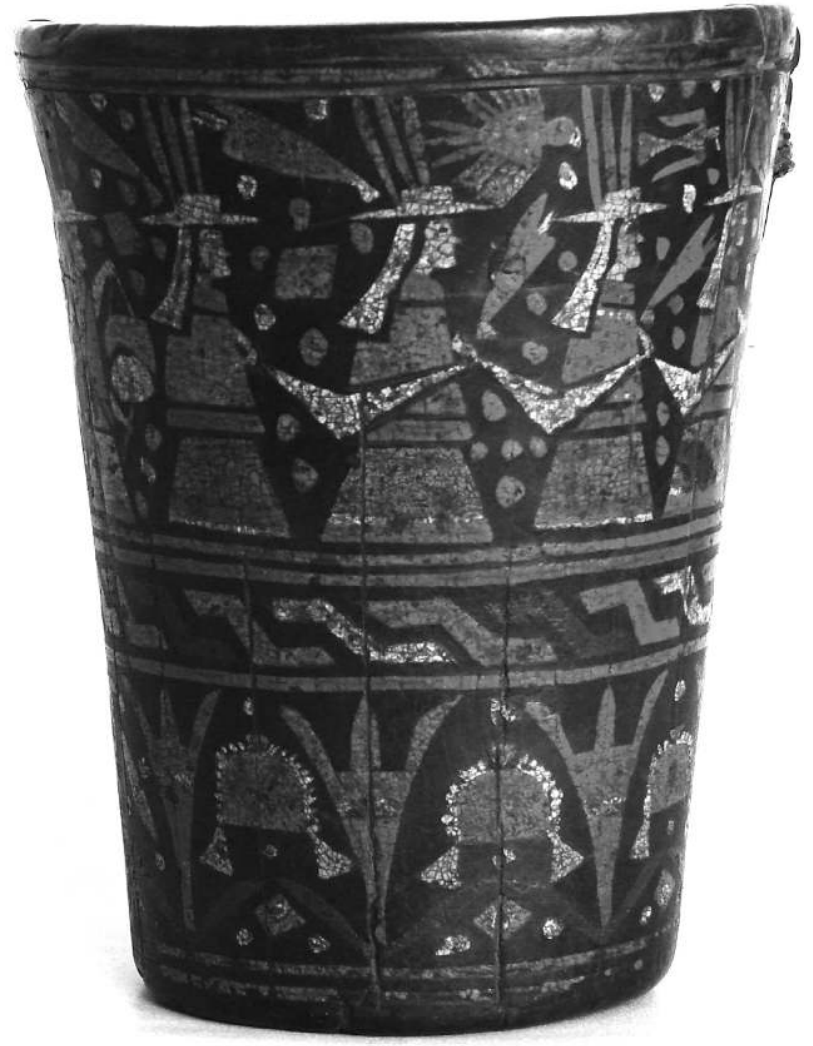

FIG. 1 - Pieza UNSA 1012-64, Coleccíon Yabar, Museo Arqueológico de la Universidad San Agustín, Arequipa [Foto José Luis Martínez].

diversos pigmentos de colores, exhiben bellos paisajes, multitudes de personajes y unas fauna y flora que sorprenden ${ }^{5}$. Se trata de un tipo de objeto que tuvo amplia circulación en el espacio andino a lo largo del período colonial y que incluso continuó hasta los albores del período republicano ${ }^{6}$, con diversas decoraciones y temas pintados en sus superficies ${ }^{7}$. Se conocen escasos antecedentes documentales respecto de su fabricación y circulación durante el período colonial, aunque sí se han realizado estudios sobre las maderas empleadas en su confección ${ }^{8}$. Por su parte, la procedencia de la gran mayoría de los ejemplares actualmente conocidos y depositados en museos o colecciones particulares es aún una incógnita, a pesar de que, entre quienes los han estudiado, hay coincidencia que el foco principal de su elaboración entre los siglos XVI y XVIII estuvo en el Cuzco y sus alrededores (Liebscher 1986; Cummins 1988; Flores Ochoa et al. 1998; Ziółkowski 2000, entre otros). Las temáticas de muchas de sus escenas y de 
sus personajes, vinculados estrechamente a una memoria colonial sobre el pasado inkaico, también apuntan en esa misma dirección. Se podría hablar, aunque sea de manera preliminar, de una tradición principalmente « cuzqueña » en su fabricación ${ }^{9}$. Hay antecedentes aislados, sin embargo, que sugieren que en ciertos lugares del altiplano andino también se fabricaron y distribuyeron queros. Es lo que señaló Vázquez de Espinoza en el siglo XVII para el área de la antigua ciudad de La Plata, hoy Chuquisaca (1969 [1630], pp. 431-432; véase Cummins 2004, cap. IX) ${ }^{10}$. Asimismo, a juzgar por la procedencia de algunos queros encontrados en comunidades aledañas al lago Titikaka, es posible postular la existencia de una tradición con algunas características propias (volveremos sobre ello más adelante). Es posible que allí se haya producido un tipo de vasos con temáticas más propias o no tan vinculadas a los cuzqueños, tal como lo han planteado Flores Ochoa et al. (1997). No se puede descartar, por lo tanto, la existencia de varias tradiciones, con temas comunes y otros propios.

\section{UN TEXTO VISUAL}

En las ilustraciones de los queros no sólo destaca la belleza de los arreglos estéticos que portan. Sólo a modo de ejemplo, quisiéramos llamar la atención del lector sobre uno de estos vasos, encontrado por Arthur Posnansky en la Isla del Sol (Figura 2) ${ }^{11}$.

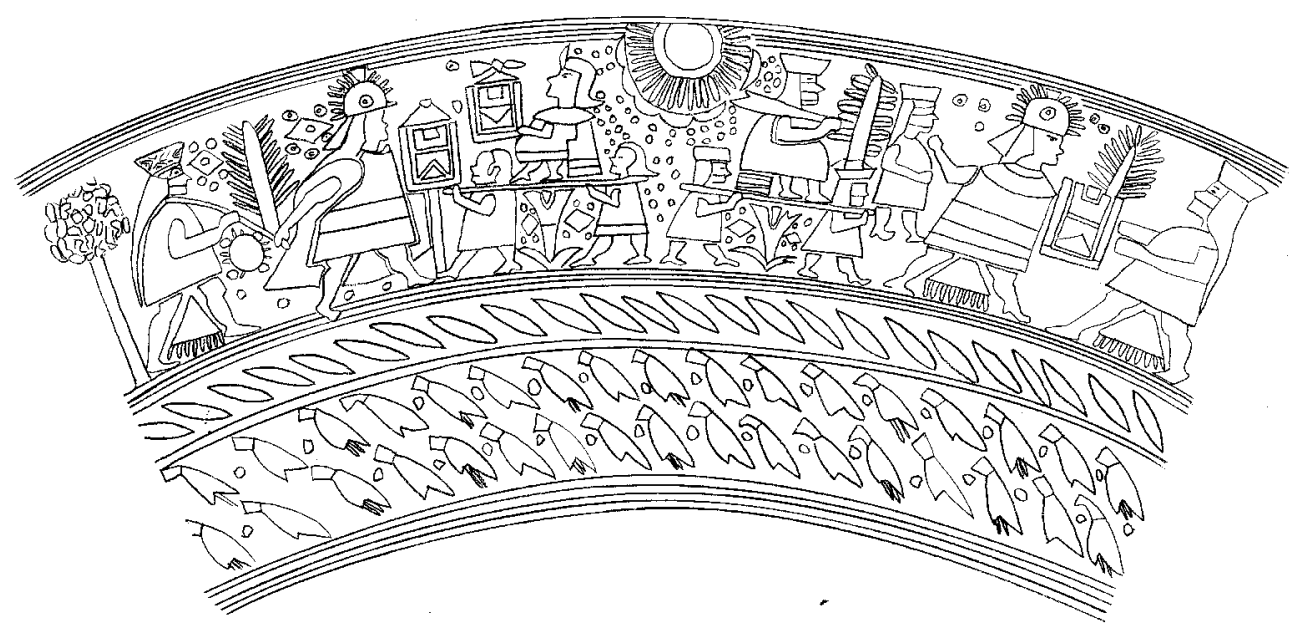

FIG. 2 - Quero que representa, en el campo superior, una escena en la que aparecen dos grupos, uno de cuzqueños (con cascos semi circulares y escudos rectangulares) y otro de guerreros de la selva, antis (con sus rostros pintados con bandas horizontales) [Dibujo Clara Yáñez, de acuerdo a Posnansky 1945, plancha XLIVc]. 
Entre plantas y árboles tropicales, en un paisaje que evoca las tierras bajas y cálidas de los Andes, se encuentran personajes que, por sus trajes, pertenecen a diferentes sociedades prehispánicas. Unos, con cascos, escudos y otros emblemas son reconocibles como soldados y autoridades cuzqueñas ${ }^{12}$; los otros, con pelo largo y rostro pintado en franjas de distintos colores, pertenecen a grupos de guerreros chunchus o antis, habitantes precisamente de esas tierras bajas orientales de los Andes.

Cuando la mirada se afina, se advierte que los personajes parecen estar agrupados en tres conjuntos. El primero, en el extremo derecho ${ }^{13}$, está compuesto por dos hombres, que caminan hacia la izquierda de la escena entre algunos árboles ${ }^{14}$; el soldado cuzqueño lleva al anti ${ }^{15}$, prisionero, conducido por una soga al cuello. Al otro extremo aparece otro guerrero inkaico que enfrenta a otros dos hombres, uno - pequeño o más lejano - ubicado a su espalda y el otro en su frente, ambos antis o chunchus. Finalmente, podemos identificar un conjunto central, compuesto de dos personajes (uno de ellos es un inka o dignatario cuzqueño y el otro usa el mismo traje que los antis) ${ }^{16}$, que son llevados en andas en los hombros de dos personas de menor tamaño, y que se dan mutuamente la espalda, dejando como centro o posible eje de toda la composición, a una imagen solar rodeada a su vez por posibles nubes, y lluvia o granizo ${ }^{17}$.

Por los elementos que hemos descrito, esta composición forma parte de un conjunto bastante popular en los queros coloniales ${ }^{18}$, que otros investigadores han denominado de diversas maneras: como temas o motivos de « relaciones con el Antisuyo » o « batallas » (Flores Ochoa et al. 1998, p. 182 ss.); « motivo Batalla y presentación » (Cummins 1988) o « conflictos armados » (Liebscher 1986, p. 58 ss.).

Resulta claro que esta composición está organizada, al menos en un plano superficial, a partir de varias convenciones visuales que remiten a un lenguaje plástico muy elaborado. Tanto el ambiente de la selva como los personajes fueron compuestos a partir de conjuntos significantes relativamente reducidos o acotados: la selva, por las plantas y árboles ${ }^{19}$; los cuzqueños, por sus cascos, escudos y trajes decorados; los antis, por sus peinados y caras pintadas, así como por sus camisas o kushmas sin decoración; las autoridades de cada grupo, por las andas; el inka o dignatario, por las plumas en su frente; el vencido, por la soga amarrada a su cuello. Ello nos habla de la existencia de determinadas convenciones visuales que parecieran ser suficientes para que un observador andino de tiempos coloniales pudiera reconocer - suponemos - con relativa facilidad el tema representado ${ }^{20} \mathrm{o}$, al menos, a algunos de sus componentes. Retomaremos este punto más adelante, ya que es posible que este procedimiento de síntesis se vincule también con otros procesos narrativos.

Un sol, a veces antropomorfizado, muy similar al que aparece aquí y en la misma posición, separando dos grupos humanos diferentes, se encuentra a su vez en otros queros coloniales, sobre todo en los que llevan escenas que se han 
descrito como un encuentro entre los inkas y los collas del borde norte del lago Titikaka $^{21}$. En algunos casos se trata de encuentros pacíficos; en otros, es posible que se metaforizaran relaciones de competencia o rivalidad ${ }^{22} \mathrm{o}$, incluso, situaciones de enfrentamiento o desencuentro ${ }^{23}$. La incorporación de un sol con nubes y posibles lluvias y/o granizo, intermediando entre las autoridades de dos grupos diferentes, independientemente de cuáles sean los grupos involucrados, lleva por tanto a plantear la posibilidad de que, además del tema primario o « central» por así decirlo (el del choque entre cuzqueños y antis), estaría funcionando en nuestra composición otro tipo de convenciones visuales, que remiten ya no tanto a un tema en específico, sino a una breve estructura significativa que, puesta aquí o allá, pudiera remitir a un significado preciso: encuentro o desencuentro. Nuevamente, nos encontramos frente a un elaborado lenguaje plástico, capaz de « decir» o de narrar visualmente. En los queros estaríamos en presencia de un tipo de textos, entonces, que, como ya lo indicamos, circularon profusamente a partir del siglo XVI.

Pero, ¿cómo funcionaban esos lenguajes visuales? Es aquí que surgen varios interrogantes, puesto que sabemos muy poco acerca de cómo estaban construidos plástica y narrativamente estos temas o motivos, y el conocimiento de las semióticas visuales puestas en juego durante el período colonial es también reducido. Quien más se ha acercado al problema que estamos planteando aquí, ha sido Cummins (2004, pp. 354-369) que postuló que, en el caso del « motivo de la batalla inkas-antis ", no se trataba de un relato histórico vinculado a los ciclos orales cuzqueños que narraban las conquistas de los inkas, sino que lo representado debía entenderse como una metaforización de batallas rituales (o tinku) entre mitades simbólicas, aún en funcionamiento en el período colonial y hasta la actualidad ${ }^{24}$.

Cummins destaca la existencia de un relato, de una narración visual en la cual el « motivo de la batalla inkas-antis » estaría constituido por distintas escenas que « describen diferentes etapas de la batalla entre los inkas y los guerreros de la selva o antis/chunchos » (ibid., p. 354), que serían metáforas de diferentes episodios de las batallas rituales. Esto nos parece central puesto que, independientemente de si aceptamos una alternativa interpretativa $\mathrm{u}$ otra (la histórica/oral, o la metafórica), lo remarcable es que los llimpikamayoq ${ }^{25}$ coloniales construyeron unos textos en los cuales era posible para un observador advertir escenas que podían corresponder a secuencias o momentos distintos de una narración mayor. La secuencia visual, tal como la analiza Cummins (ibid., p. 360 ss.), tiene al menos dos momentos, el del enfrentamiento o batalla, en el cual los combatientes del lado cuzqueño aparecen en la mitad derecha o hanan del plano pictórico ${ }^{26}$ en tanto que los antis se ubican, indefectiblemente, en la posición urin, la inferior o subordinada según los esquemas simbólicos andinos. Un segundo momento correspondería al de la derrota de los antis, en el cual al menos un prisionero anti vencido y sin armas, amarrado con una soga por el 
cuello, es conducido por un combatiente cuzqueño ante la presencia del Inka, que generalmente aparece sentado en su tiana o asiento de gobernante, exhibiendo todos sus emblemas de poder. Los queros muestran únicamente estas dos escenas, con exclusión de las muchas otras que podrían haberse representado si se tratara de un relato visual que siguiera al pié de la letra a un relato oral.

Se trataría, entonces, de un tipo de textos visuales que mostraban escenas; esto es, personajes que realizan acciones que no son aisladas, sino que poseían, como tal escena, un determinado sentido y estructura y que, al mismo tiempo, podían dar cuenta de una cierta temporalidad, de momentos o etapas diferentes que, probablemente para quienes veían y usaban esos queros, formaban parte de un mismo ciclo narrativo. En el caso presente, el del quero publicado por Posnansky, la escena que acabamos de describir correspondería precisamente a uno de esos momentos de las varias etapas que conformaban « la batalla entre los inkas y los guerreros de la selva » tal como lo señaló Cummins (ibid., p. 354).

$\mathrm{Si}$ en los queros estaban inscritas escenas que remitían a temáticas importantes para las poblaciones andinas, y si estas escenas constituyeron parte de discursos acerca de distintos aspectos de la vida colonial y de las memorias de esos hombres y mujeres andinos sobre su pasado anterior a la invasión europea, ¿cómo funcionaban? No queremos abordar aquí una discusión acerca de los temas a los que se referían esas escenas, sino a la manera en la que ellos fueron construidos, presentados y leídos. Si estamos en presencia de relatos, enunciados por andinos coloniales, ¿es posible encontrar en otros lenguajes de esas sociedades algunas pautas comunes, que nos permitan entender mejor la construcción de estas narrativas visuales?

Otros investigadores han avanzado sobre estos posibles planos de relación entre distintos soportes. Se han planteado, por ejemplo, relaciones entre los discursos musicales y textiles (R. Martínez 2009) y se ha enfatizado, igualmente, que ciertos textos visuales presentes en los queros circularon también en vasos de cerámica o de plata. Cummins (2007) ha explorado las relaciones de sentido existentes entre diversos soportes, más allá de sus materialidades diferentes. Nuestra pregunta parece válida entonces, si se acepta, como proponemos, que los textos visuales compartieron con otras semióticas (expresadas en distintos soportes), ciertos modos y estrategias de construcción narrativa. En el caso que queremos abordar aquí, nuestra aproximación privilegia las operaciones de construcción de esos relatos más que la circulación de significantes en uno u otro tipo de materialidad.

En trabajos anteriores postulamos la existencia de prácticas comunicativas andinas redundantes, esto es, que ciertas unidades de sentido y determinados relatos podían ser enunciados a través de diferentes soportes ${ }^{27}$. Esto es claro, por ejemplo, entre algunas narrativas orales y otras visuales de las que el ciclo de las guerras entre los cuzqueños y los chankas es un ejemplo bastante conocido. Sabemos que en algún lugar cercano al Cuzco existía una pintura rupestre que 
habían mandado a hacer los inkas, que recordaba a los viajeros los episodios de la huida del Cuzco del Inka Yawar Wak'aq y la defensa de la ciudad por parte de Wiracocha Inka, ante la amenaza de los enemigos chankas (Garcilaso 1991 [1609], libro V, cap. XxIII, tomo I, p. 306). También existieron numerosos relatos orales sobre esos mismos acontecimientos, de los cuales dieron cuenta posteriormente los varios cronistas que los recogieron y escribieron acerca de ellos (Betanzos 1987 [1551]; Cieza de León 1986 [1550]; Sarmiento de Gamboa 2001 [1572], por mencionar algunos de los más conocidos). Y es posible que esos mismos relatos tuvieran una versión bailada y cantada, que se representaba cuando los inkas recordaban sus triunfos (Betanzos 1987 [1551], cap. XIII, p. 61$)^{28}$. Un mismo ciclo narrativo podía circular, entonces, a través de distintos soportes. Nos parece claro que la simultaneidad de esta redundancia debe ser entendida no como un momento de la enunciación, sino como una posibilidad para quien perteneciera a esa sociedad y transitara por los diversos espacios o entornos en los que esos relatos circulaban, ya fuera oral, visual o musicalmente. En esta perspectiva, es cierto, habría que matizar esa simultaneidad en algunos casos con la idea de una complementariedad en la transmisión y circulación de esas narrativas.

A pesar de no ser un rasgo exclusivo de las narrativas andinas coloniales, la redundancia implica, desde nuestra propuesta metodológica, que un discurso (con sus variantes) pueda manifestarse en distintos soportes de tal manera que su lectura, ya sea en conjunto o separadamente, permita tener una visión general y complementaria del discurso ${ }^{29}$. En este sentido, podemos mencionar como ejemplo la articulación del relato del baile de la soga en al menos dos tipos de soportes: narrativo y quero (Figura 3$)^{30}$.

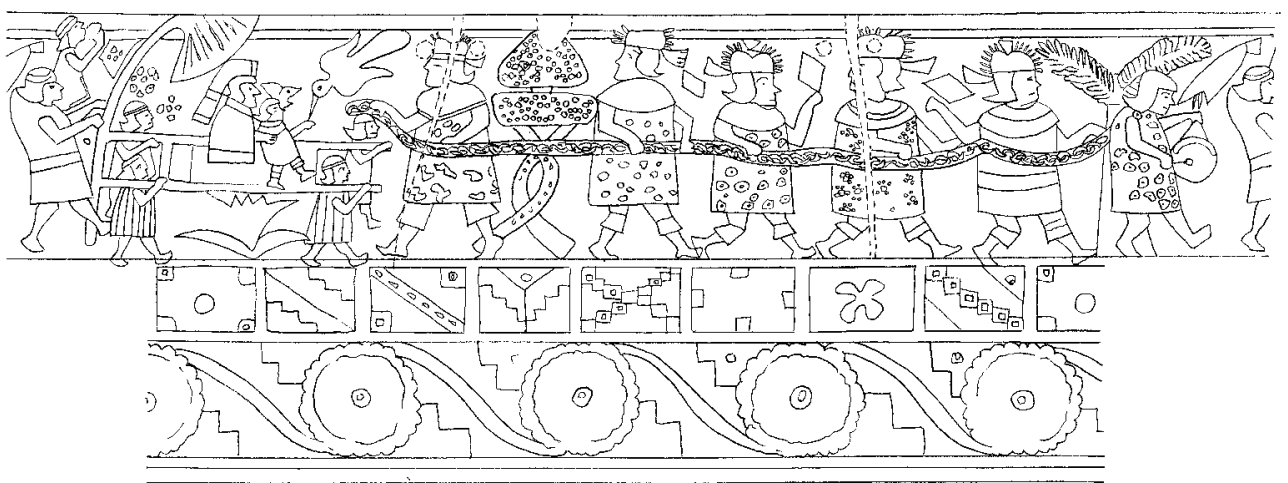

FIG. 3 - Representación del baile de la soga. Pieza UNSA 0183, Museo Arqueológico de la Universidad San Agustín, Arequipa [Dibujo Clara Yáñez, Proyecto FONDECYT 1090110]. 
[...] a una cassa que llaman moro urco, que estava junto a las cassas del Sol, a sacar una soga muy larga que allí tenían coxida, hecha de quatro colores: negra, y blanca, y bermeja y leonada, al prinçipio de la qual estava hecha una bola de lana colorada gruessa. Y venían todos las manos asidas en ella, los hombres a una parte y las mujeres a otra, haciendo el taqui llamado yaguayra. (Molina 2010 [1575], p. 81) ${ }^{31}$

Se trata, en este caso, de un ritual que realizaba el Inka gobernante, o Zapan Inka, para simbolizar la toma de posesión de nuevos territorios o para traspasar a sus descendientes y deudos algunos de los recientemente conquistados (Zuidema 1989) ${ }^{32}$, y Garcilaso de la Vega (1991 [1609], libro IX, cap. I) cuenta que fue en una de esas celebraciones rituales que el Inka Wayna Qhapaq aprovechó para celebrar el nacimiento de su hijo Titu Kusi Yupanqui, más tarde conocido como Wasqar Inka, en referencia a la wasq'a o soga usada en ese ritual. Cabe mencionar que, si bien esta relación pudiera ser abordada como la « ilustración » gráfica del relato oral, una mirada analítica - desde nuestra perspectiva - debiera apuntar más bien a develar aquellos rasgos que son específicos de cada tipo de soporte en la transmisión del mensaje o relato específico, hecho que sólo es posible gracias a un minucioso estudio, no solamente de la pieza o texto en cuestión, sino también de su vinculación con el sistema completo del soporte.

No se trata de la única relación existente entre oralidades y lenguajes visuales. Veámoslo.

\section{ORALIDAD Y VISUALIDAD EN LOS ANDES COLONIALES}

Existe un consenso respecto de que uno de los rasgos más comunes de la estructura de la poesía quechua era el paralelismo semántico (Husson 1985, 2002; Itier 1992; Fossa 2005; Manheim 1991), un tipo de estructura en el que predominaban los pares o dobletes ${ }^{33}$ ya sean semánticos o morfosintácticos. Itier (1992, p. 1013) lo denominó el « ideal sinonímico » y Fossa (2005, p. 40) lo señala como una característica presente en diversas lenguas amerindias, tanto entre los mayas prehispánicos como entre las poblaciones kunas contemporáneas. Se trata de un tipo de forma poética que Husson (2002, p. 391) contrastó con otras, por ejemplo la poesía europea. Su principio operante es la construcción de secuencias que poseen una estructura sintáctica en la cual se construye una relación entre dos términos en los que, de acuerdo a Itier, uno puede ser subordinado a otro (Itier ibid.). Veamos, como ejemplo, un fragmento de una canción que transcribe Guaman Poma:

¿Es el infortunio, reina, que nos separa?

¿Es la desgracia, princesa, que nos separa?

¿Es por ser tú mi florecilla azul, mi flor amarilla?

En mi cabeza, 
En el centro del corazón

Te llevaría a todas partes. Como un espejo de agua eres una ilusión.

Como un espejo de agua eres un engaño.

¿Dónde estás? ¿Descansaré con mi amada? [...] (Guaman Poma 2004 [1616], f. $317[319])^{34}$

No nos referimos aquí sólo a una posible relación de simetría o sinonimia entre un relato oral y una narración visual, sino también a una característica de las formas poéticas al interior de un mismo texto. Se trata, entonces, de un enunciado que puede repetirse, ya sea dos veces de manera igual o con términos del mismo campo semántico. Los enunciados paralelos son, así, secuencias de un mismo par que presentan semejanzas, que contienen una afinidad semántica, ya sea por la presencia de sinónimos, de parasinónimos o porque remiten a un campo léxico común, que Husson (2002, p. 392) denomina « paralelismo semántico » (los casos en negritas de nuestro ejemplo). Habría tres tipos de apareamientos semánticos: antónimos, cohipónimos y sinónimos (Itier 1992, p. 1013), a los cuales podemos añadir un cuarto, propuesto por Husson; esto es un mismo término que se repite y que denomina « doblete ».

¿Es posible reconocer estas estructuras sintácticas verbales en algunos queros? De ser así, ¿se trataría de un mismo tipo de procedimiento de construcción narrativa, ya sea tanto para textos orales como visuales? Proponemos que el paralelismo sería un tipo de estructura visual que se encuentra ya en los queros pre-toledanos de la segunda mitad del siglo XVI y que continuó presente al menos a lo largo de todo el siglo XVII, aunque después de las transformaciones sociales provocadas durante el gobierno del virrey Toledo se desarrollaron también - y fuertemente - otras estructuras narrativas.

Entre los distintos temas narrativos que se pueden identificar en los queros coloniales, hay uno que ha llamado la atención de numerosos especialistas. Nos referimos a un conjunto que Liebscher (1986) denominó como "motivos de arcoíris ${ }^{35}$ y que estaba asociado a antiguos temas andinos, como la representación de las autoridades y el poder, así como los de la fertilidad y los momentos de cambio (Cummins 2004, p. 369 ss.; Martínez C. 2012). Los queros con este motivo muestran siempre una misma estructura organizativa: tres campos horizontales entre los que se distribuyen las imágenes. En el campo superior se ubican dos arcoíris que surgen de ambos lados de la cabeza de dos felinos. Sobre estas cabezas suelen aparecer plantas, aves, escudos o, incluso, personajes femeninos o masculinos. Bajo los arcoíris se dan fundamentalmente dos posibilidades de presentación, que son las más recurrentes; ya sea un hombre mirando hacia el arco siguiente y una mujer en el otro, a su vez orientada hacia el personaje masculino ${ }^{36}$; o una pareja, masculino-femenina, ambos bajo un mismo arco (lo que se repite a su vez en el siguiente) ${ }^{37}$. De la muestra analizada en este artículo, podemos señalar que muy pocos ejemplares muestran la aparición exclusiva de un hombre, o una mujer o un ave heráldica, lo que nos 
lleva a pensar que las posibilidades de presentación parecen, así, ser variantes de una organización semántica compuesta por la pareja hombre-mujer ${ }^{38}$. Las posibilidades de presentación parecen, así, ser variantes de una organización semántica compuesta por la pareja hombre-mujer.

Lo que nos interesa aquí es ver cómo se construyó esta narración visual, cuáles fueron las maneras de articularla. Es sorprendente que haya un número significativo de queros en los que se grabaron y pintaron dobletes ${ }^{39}$. Como ejemplo, en la Figura $4{ }^{40}$ puede verse un personaje central que aparece ubicado bajo un arcoíris (o $\left.k^{\prime} u y c h i\right)$ : se trata de un soldado cuzqueño con chuku o casco, escudo y lanza en cada mano, vestido con un largo unku prehispánico, que aparece flanqueado por dos aves. Es la misma figura que se repite, sin cambios, al otro lado de la superficie curva del vaso. La noción de doblete está remarcada, además, por el segundo grupo de imágenes: desde la parte superior de la cabeza de cada felino (se advierten sus orejas y cejas) surge una planta con cinco flores. Este conjunto también se repite exactamente igual.

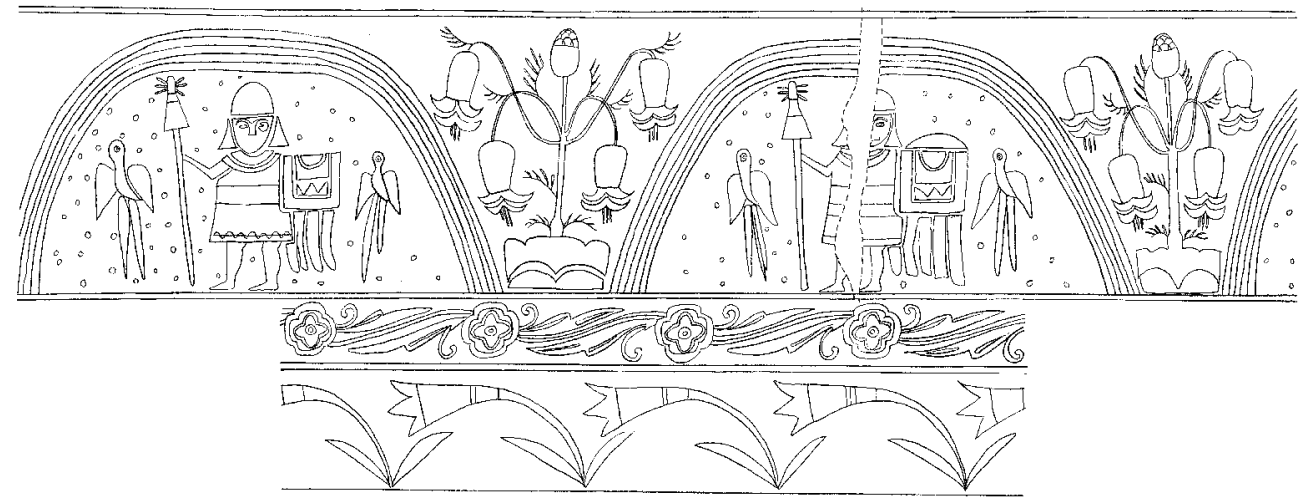

FIG. 4 - Quero con un enunciado compuesto a partir de la estructura de paralelismos semánticos del tipo « dobletes ». Pieza Momac 85, Museo Inka-UNSAAC, Cuzco [Dibujo Clara Yáñez, Proyecto FONDECYT 1090110].

Nos parece que la estructura de esta imagen visual corresponde a la de los dobletes tal como han sido descritos por Husson (2002) y que reseñamos brevemente. Es importante destacar que aparecen casi exclusivamente, en nuestra experiencia, dentro de los queros con el motivo arcoíris. La Figura 4 ilustra dos ubicaciones para los dobletes: bajo los arcoíris, y entre ellos (esta última posibilidad, con una ocurrencia total de 55 ejemplares de la muestra analizada aquí). Además, como lo mostraremos en breve, la ocurrencia bajo los arcoíris no es privativa de los dobletes, sino que se comparte con los pares semánticos.

Si bien la estructura narrativa de los dobletes es la más frecuente ya que está presente en todas las variantes que describimos más arriba, no es, con mucho, la 
única manera de estructurar la narración acerca de los personajes ubicados bajo los arcoíris. Es precisamente la existencia de distintas posibilidades de articular el texto visual la que nos lleva a postular que se trata de una estructura de composición semántica y no una opción decorativa.

Nos ha sido mucho más difícil identificar el paralelismo semántico, la segunda forma de articulación que utilizaba términos que, sin ser los mismos, remiten a un campo léxico común y en el que, siguiendo a Itier (1992), el estatuto de cada término sería desigual, ya que a un primer término, le sigue otro, « más restringido » (ibid., p. 1013). Nos parece que esto proporciona interesantes pistas para nuestra búsqueda. Si volvemos al conjunto del motivo « arcoíris » lo que se encuentra es que hay diversas sustituciones que reemplazan alguno de los dos términos masculino-femenino que debieran estar ubicados dentro de uno de los dos arcoíris. En la Figura $5^{41}$, por ejemplo, hay un personaje femenino que viste un aksu o anako ${ }^{42}$ y lliqlla o mantilla y lleva en su mano una rama de kantuta (Cantu buxifolia) ${ }^{43}$ con dos flores, y una amaru ${ }^{44}$ o serpiente alada que se ubica bajo el segundo arcoíris. En ambos campos dentro del arcoíris, también aparecen flores acompañando a los personajes centrales, pero mientras en el primer caso hay una misma flor (no identificada) en ambos costados de la mujer, en el segundo aparece una pequeña flor de ñuqchu bajo la amaru y frente a ella una mata que parece ser de maywa (Stenomesson incarnatum).

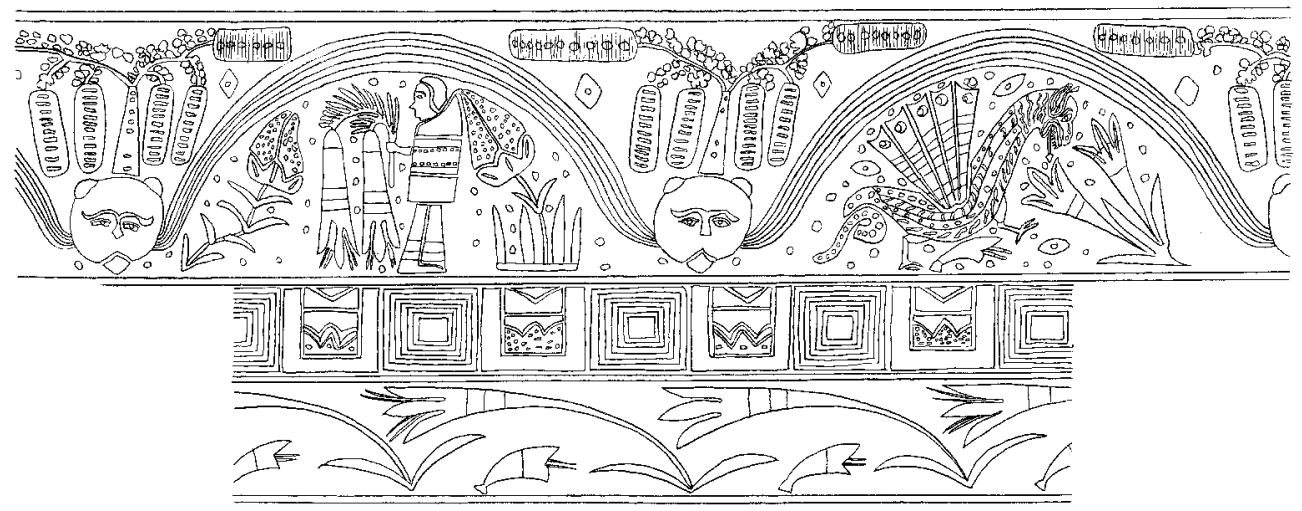

FIG. 5 - Quero con posible paralelismo semántico en la figura central y doblete en el conjunto felino-planta. Pieza Mo 10395, Museo Nacional de Arqueología, Antropología e Historia del Perú, Lima [Dibujo Clara Yáñez, Proyecto FONDECYT 1090110].

Aquí se abren dos posibilidades interpretativas, dependiendo de los datos que se analicen. La primera es postular una relación entre las quya y las amaru, tal como lo sugiere Zuidema cuando señala que este tipo de seres estaría relacionado a lo femenino, ya que Mama Waqo, la mujer mítica fundadora del Cuzco junto a 
Manqu Qhapaq, era de la «casta de los amarus » (1989, pp. 268-269). Si esto es correcto, tendríamos efectivamente un paralelismo semántico ya que la amaru formaría parte del mismo campo de significados que la imagen femenina ubicada en el primer arcoíris. Se trata de un segundo término "más restringido », siguiendo a Itier, ya que el primero es más amplio (lo femenino) respecto del segundo, en el que la amaru representa sólo una de las posibilidades de ese femenino.

Pero creemos que es posible también interpretar esta estructura en un nivel narrativo más complejo, una segunda opción que hace alusión al motivo « arcoíris » tal como lo revisamos más arriba, compuesto por diversas variantes de una estructura significante « hombre-mujer ». Aquí el paralelismo semántico podría ocurrir entre una figura que ha sido reemplazada, esta vez la masculina, y la que está presente, la amaru. Si esto es correcto, ambas figuras deberían remitir a un mismo campo ya sea semántico o léxico. Esto requiere de una explicación más detallada. ¿Qué relaciones significantes existían para que una amaru pudiera sustituir a un personaje masculino y, aun así, conservar la misma proposición narrativa propia del paralelismo semántico con la mujer ubicada bajo el otro arcoíris? Creemos que una respuesta está dada en las posibilidades que tenían algunos inkas de transformarse en esos seres. Era el inka, masculino, el que podía transformarse en amaru, tal como lo hizo Ataw Wallpa para fugarse de la prisión a la que lo había sometido Wasq'ar Inka (Cieza de León 1986 [1550], p. 208; Zárate 1995 [1555], p. 62). Por su parte, Pachacuti Yamqui Salcamaygua (1993 [1613?], f. 21v) relata que, cuando nació Amaru Yupanqui, hijo de Pachakuti Inka, en las cercanías de la ciudad del Cuzco salió una yauirca o amaru " muy fiera bestia, media legua de largo y gruesso de dos braças y medio de ancho $\gg{ }^{45}$. En esta segunda posibilidad, las amaru están estrechamente vinculadas a lo masculino. No disponemos, por ahora, de otros materiales para dilucidar mejor esta cuestión.

¿Podría significar esto que las imágenes grabadas y pintadas en los queros eran decodificadas y relatadas siguiendo principios que también se encuentran en la oralidad? ¿Que algunos procedimientos de la oralidad, tales como el paralelismo semántico en cualquiera de sus posibilidades, también tenían aplicación en la construcción de los textos visuales? Si se piensa en la información acerca de los quipus, que eran «leídos » y relatados (también bailados) ${ }^{46}$, siguiendo igualmente procedimientos lingüísticos (Fossa 2011), es posible, entonces, postular una vinculación entre la construcción de narrativas orales $\mathrm{y}$ visuales.

¿Siguió la construcción de las narrativas visuales sobre los queros algunos procedimientos de construcción similares a los de los relatos orales o escritos quechuas coloniales? A pesar de las fuertes influencias de la escritura y la pintura europeas en el siglo XVII, ¿sería posible identificar otras operaciones de organización del relato o de sintaxis comunes a ambos tipos de lenguajes, visuales 
y lingüísticos? ¿Cómo comparar o relacionar imágenes (su presentación, ordenamiento, posibles secuencias) con los pocos textos escritos por indígenas que se conocen o con los escasos fragmentos de relatos orales en quechua insertos en algunos de esos textos? En lo que sigue usaremos para este análisis básicamente tres textos escritos por andinos a finales del siglo XVI y en el primer cuarto del siglo XVII: el documento conocido como Ritos y Tradiciones de Huarochirí (1608?), la Relacion de antiguedades deste Reyno del Piru, de Pachacuti Yamqui Salcamaygua (1993 [1613?]), y El primer nueva corónica y buen gobierno (2004 [1616]) de Guaman Poma. Los tres son textos coloniales, producidos en un contexto histórico similar a aquel en que fueron elaborados los queros, sometidos a parecidas demandas sociales, políticas o religiosas. Se trata de textos que, como bien lo señaló Salomon (1994, p. 230), son « saturadamente coloniales ». Y esto incluye, por cierto, al documento huarochirano, no ajeno a las influencias librescas de su tiempo ${ }^{47}$.

Para explorar estas posibles relaciones trabajamos con un concepto operativo: el de modos narrativos, o tipos de relato en los que es posible identificar acciones, unidades temáticas y lógicas organizadoras. Insistimos en el carácter operativo del concepto, puesto que lo entendemos como una herramienta para abordar el análisis de ciertas unidades narrativas, especialmente de las visuales. En base a este concepto pudimos identificar al menos dos modos narrativos presentes tanto en los relatos orales o escritos andinos coloniales como en las narraciones visuales inscritas en los queros ${ }^{48}$. Uno, que denominamos " simple », o « único » en sus ejes narrativos y composicionales, caracterizado porque la acción que ocurre es una sola, y transcurre en un mismo tiempo. $\mathrm{Y}$ un segundo tipo, que denominamos "complejo", en el que al modo narrativo simple se le agregan o introducen fragmentos de otros relatos (unidades temáticamente distintas), o en que el ordenamiento temporal no es secuencial $u$ otros en que la narración se encuentra reducida a elementos mínimos. En todas estas narraciones "complejas », la lógica organizadora parece ser distinta de aquella presente en los tipos « simples ».

\section{El modo narrativo " simple "}

Este modo narrativo se encuentra en textos cuya organización muestra una unidad, al menos temática, tal como lo enseña este cantar de Inka Yupanqui que Fossa identifica como un jarawi, un tipo de canto practicado al fallecer un gobernante, y de rememoración u origen (Fossa 2005, p. 35):

Desde que florecía

Como la flor del huerto hasta aquí

He dado orden y razón

En esta vida y mundo

Hasta que mis fuerzas bastaron

Y ya soy tornado tierra (Betanzos 1987 [1551], p. 149) ${ }^{49}$ 
Es posible identificar el modo «simple» en un número importante de queros ${ }^{50}$, en los cuales se desarrolla la narración de una única escena, con personajes unidos en una misma acción y que transcurre ya sea en un tiempo prehispánico o en uno colonial (Figura 6) ${ }^{51}$.

En esta pieza todo apunta a la unidad y al desarrollo de la escena. El momento colonial se hace explícito tanto por los trajes con capotes y pantalones bombachos de los músicos que preceden al conjunto de bailarines, como por los pantalones cortos y sueltos que llevan los danzantes. Hay otros detalles que apuntan en el mismo sentido temporal: el contexto urbano denotado por la casa con techumbre de tejas que aparece entre la comparsa, así como el perro que sigue al primer danzante. Y todo guarda relación con el tema central: la ejecución de un baile de chunchos. Se trata de una sola acción, con un único tema y una unidad temporal definida.

\section{Los modos narrativos " complejos"}

Hemos podido identificar al menos cuatro modalidades de complejidad presentes tanto en los textos escritos estudiados como en los visuales de los queros. El elemento compartido para ponerlas en esta categoría es el hecho de que la narración de base ha sido intervenida de alguna manera, ya sea a) agregándole unidades de otros relatos, o b) presentando secuencias distintas de un mismo tema, que debieran - visto desde una perspectiva occidental - estar separadas u ordenadas de una manera secuencial y que no lo están; c) ya sea complejizando los tiempos del relato; o, finalmente, d) reduciendo la narración antes extensa a una presentación mínima.

\section{La presencia de dos tiempos en una misma unidad textual}

Se trata de una estructura presente en varios queros ${ }^{52}$, aunque es evidente que no fue un tipo de construcción narrativa exclusiva para los Andes. Otros ejemplos, como los presentes en el Antiguo Testamento, sugieren que son procedimientos vinculados a las oralidades ${ }^{53}$. En la copa que se presenta en la Figura $7^{54}$ se encuentran dos escenas: una que corresponde a un tiempo prehispánico - un enfrentamiento entre inkas y antis o chunchus -, y otra que corresponde a una escena de un ritual de siembra en el que los personajes están vestidos con vestimentas coloniales.

Ambos tiempos, pasado y presente (desde la perspectiva colonial), comparten un mismo soporte y la misma superficie. Lo que queremos destacar aquí es que aparentemente una misma narración, sea oral, escrita o visual, podía referirse, en la misma enunciación a ambos tiempos, en una lógica de relato que admite la presencia de ambos, como una unidad complementaria para la que el paso entre uno y otro tiempos narrativos no fuera una contradicción, sino más bien una posibilidad de enunciación, como si los límites de ellos no fueran excluyentes, de 


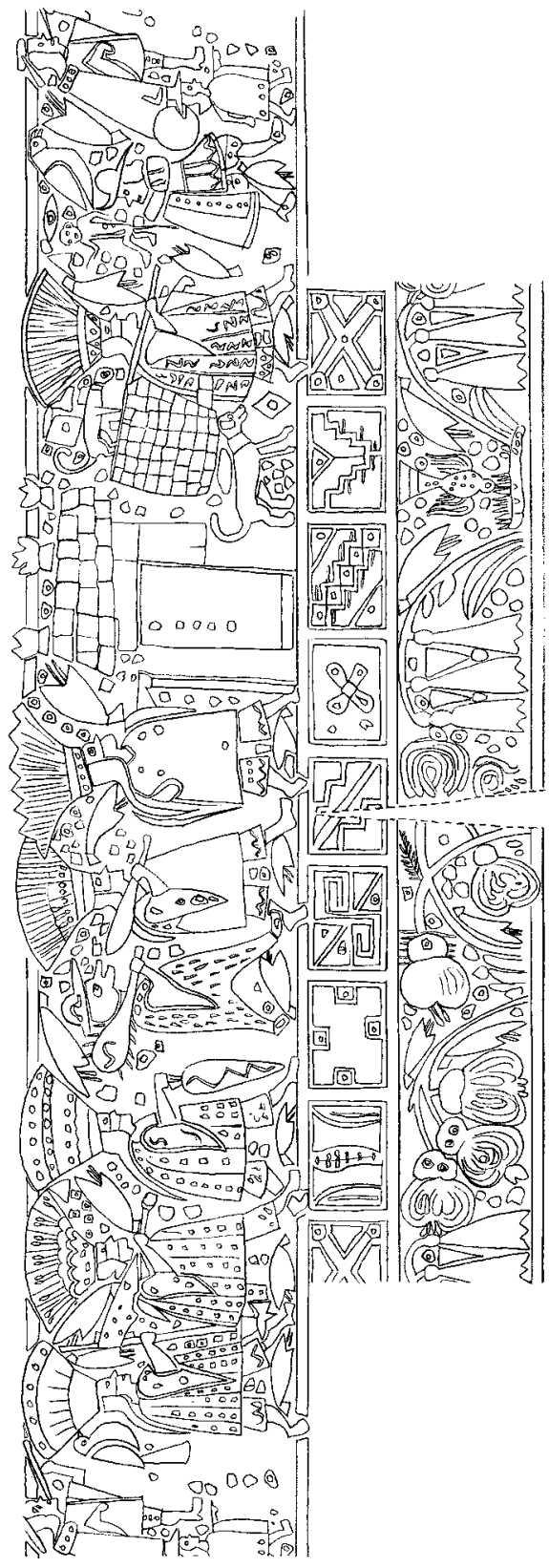

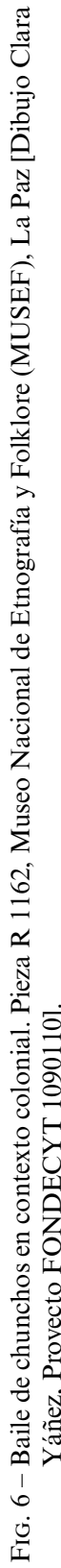



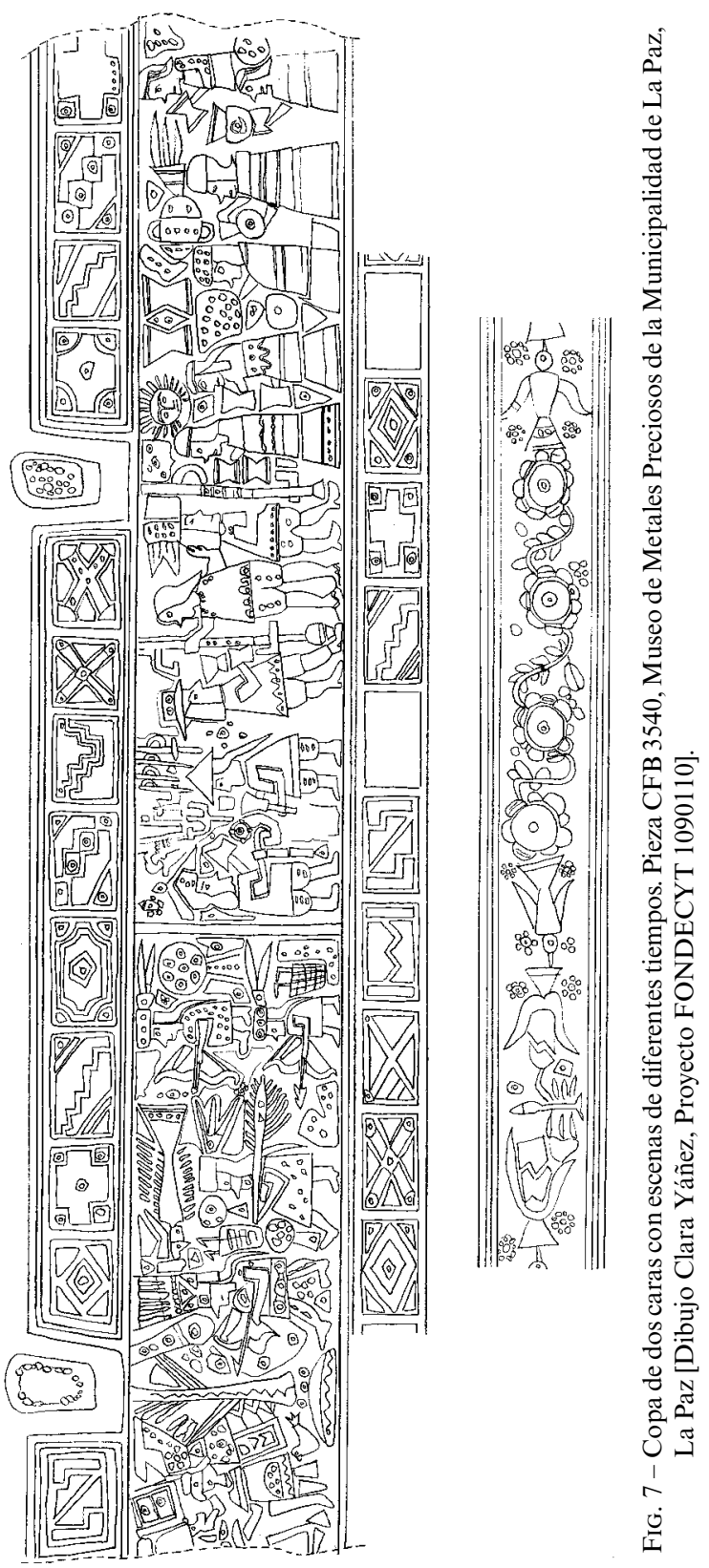
manera tal que se pudiera transitar entre un tiempo narrativo y otro. Ésta es una condición permanente en gran parte del texto del Manuscrito de Huarochirí. Sus redactores lo expresaron claramente: « No sabemos muy bien si este [Cuniraya] existía antes o después [de Huallallo Carhuincho] y de Pariacaca », o, "Aquí vamos a escribir sobre lo que hemos mencionado en el segundo capítulo, es decir: si Cuniraya existía antes o después de Pariacaca $"{ }^{55}$. La exigencia impuesta al relato por el pensamiento cristiano español requería de un ordenamiento claro y no permeable, en el que el pasado no puede coexistir con el presente, no existe ambigüedad entre un tiempo y otro ${ }^{56}$. En cambio, en el mismo Manuscrito de Huarochirí se pasa sin contradicción de una narración que apela a un pasado prehispánico (o purum pacha) y que ocupa los primeros 20 capítulos del manuscrito, a una narración que está expresada en tiempo presente, con referencias a la vida colonial, que se encuentra entre el capítulo XXI y XXVII. Ahí se relata, sin ningún corte o explicación necesaria, un conjunto de situaciones de tiempo presente, para retomar, en el mismo capítulo XXVII, el relato sobre los tiempos pasados, tal como estaba al inicio del texto. Lo que nos parece sugerente es que se trata de una estructura significativa y ordenadora, pasado-presente, que se encuentra también en al menos otro texto contemporáneo a los queros: la Nueva Corónica de Guaman Poma. En ésta, ese ordenamiento es explícito y evidente. Por una parte, hay una gran unidad referida a la memoria sobre el pasado prehispánico (la Nueva Corónica), que abre el relato sobre el mundo andino con la siguiente expresión: « [...] unas historias de nuestros antepasados agüelos y mis padres y señores rreys que fueron antes del Ynga y después que fue desde Uari Uira Cocha Runa y Uari Runa y Purun Runa » ${ }^{57}$ (Guaman Poma 2004 [1616], f. 6) Y la segunda parte, abocada a una descripción y denuncia de las condiciones de la vida colonial (el Buen Gobierno).

\section{Un orden « autónomo » de las secuencias}

En el Manuscrito de Huarochirí se encuentra la siguiente situación: en el primer capítulo se describen los tiempos «muy antiguos» (ancha ñawpa pachaca), en los que los hombres no morían sino que resucitaban:

- Dicen que en los tiempos muy antiguos había unos huacas llamados Yanañamca y Tutañamca

- A estos, en una época posterior, los venció otro huaca llamado Huallallo Carhuincho

- Después de haberlos vencido, era Huallallo quien animaba a los hombres a los cuales no consentía que engendrasen más de dos hijos

- Uno se lo comía

- El otro, el preferido, era criado por los padres En aquella época los hombres resucitaban solo cinco días después de morir (Taylor 1987, cap. I, p. 45) 
Después de 26 capítulos, en los que se escribieron y relataron mitos, rituales y prácticas de las poblaciones andinas de la sierra central peruana, el texto retoma, sin ninguna justificación ni manifestación de causa, el mismo tema, casi con las mismas expresiones de lo anotado en el primer capítulo:

Vamos a describir cómo en los tiempos antiguos los hombres decían al morir que iban a volver al cabo de cinco días.

Se dice que en los tiempos muy antiguos, cuando un hombre moría, velaban su cadáver durante cinco días (ibid., cap. XXVII, p. 411)

Es decir, se trataría de fragmentos de una misma secuencia que aparecen dispersos dentro de un texto mayor, y que se retoman sin que aparentemente se requiera de una mayor justificación. En algunos textos europeos coloniales, se encuentra también ese retorno al tema inicial, pero es introducido, al menos, por una explicación ${ }^{58}$.

Otra práctica frecuente en algunos textos con matrices orales quechuas se encuentra, asimismo, en el ordenamiento de las secuencias de un determinado ciclo mítico. Uno de los mitos fundadores de la historia del surgimiento del Tawantinsuyu como entidad dominadora en los Andes y de alcances imperiales, es el ciclo de la defensa de la ciudad del Cuzco, la capital inkaica, frente a la amenaza de invasión de otro señorío rival, los chankas. A partir de la defensa exitosa del Cuzco y posterior derrota de los invasores, Pachakuti Inka emprendió las reformas del estado cuzqueño y desarrolló las políticas expansionistas que dieron lugar al desarrollo del Tawantinsuyu que conocieron algunos tiempos más tarde los españoles. Mientras los cronistas europeos y el Inca Garcilaso ${ }^{59}$ nos presentaron un relato en el que todos los episodios del enfrentamiento entre los cuzqueños y los chankas ocurrían durante los gobiernos de Wiraqocha Inka y Pachakuti Inka (o entre Yawar Wak'aq Inka y Wiraqocha Inka, si se sigue la versión de Garcilaso), en el texto de Guaman Poma, el relato se encuentra parcialmente dentro del ciclo de Manqu Qhapaq Inka, el fundador del Tawantinsuyu, y también dentro del ciclo de Yawar Wak'aq Inka. Es decir, en tiempos de la fundación del Tawantinsuyu y con hechos atribuidos a varios gobernantes no secuenciados cronológicamente. Aquí no aparece el « orden » cronológico y la secuencialidad impuesta en las crónicas europeas.

Como en el texto de Huarochirí, Guaman Poma no parece tener la necesidad de aportar algún argumento explicativo de este diferente ordenamiento de las secuencias. En el tiempo de Manqu Qhapaq Inka, hubo, según el cronista andino, un enfrentamiento entre el Inka y el señor de los chankas, que concluye con la huida de este último hacia las tierras selváticas del Antisuyu. Pero quien conquistó la " provincia de los chankas » habría sido Yawar Wak’aq Inka. La separación física (dentro de la escritura misma) y temporal (en el orden de la narración) es enorme y evidente. Los episodios atribuídos a Manqo Qhapaq Inka se relatan en la p. 85 en tanto que los relativos a Yawar Wak'aq Inka ocurren 
en la página 105. Temporalmente, se trata del primer y del séptimo inkas, respectivamente. Pareciera que las narraciones orales estaban compuestas de unidades articuladas que podían ser narradas en órdenes aleatorios, algo que por lo demás ya mostró Ong respecto de la estructuración de muchos relatos orales en distintas sociedades (1987).

Nos parece que en los queros se puede apreciar una situación similar. Es lo que podemos advertir en los relatos visuales sobre otro ciclo mítico, el de la expansión cuzqueña hacia las tierras bajas orientales. Existe un grupo de vasos en los que aparecen dos episodios de ese ciclo: el enfrentamiento entre cuzqueños y antis (de los que ya hemos visto algunos casos en este trabajo) ${ }^{60} \mathrm{y}$ el de la victoria cuzqueña ${ }^{61}$ (Figura 8). El ciclo aparecería, aquí, completo ${ }^{62}$ : enfrentamiento inicial y posterior victoria cuzqueña sellada con la presentación de prisioneros al Inka, que aparece sentado en una tiana, el asiento emblemático de las autoridades andinas.

Lo interesante es que ambas escenas («batalla» y «presentación de vencidos ») circulaban también independientemente. Tenemos un conjunto de queros en los que se representó únicamente una de ellas ${ }^{63}$; nuevamente, y tal como lo sugieren los textos escritos y orales, se trataría de unidades narrativas que podían funcionar de manera separada. Es lo que se puede apreciar en las Figuras 9 y $10^{64}$ y supone la existencia de un meta-relato, conocido por los observadores de los queros, dentro del cual esas secuencias autónomas conservaban su significado.

\section{La inclusión de fragmentos de distintos temas en un mismo relato}

Esta inclusión puede consistir simplemente en una variante del modo narrativo anterior o constituir un submodo específico de enunciación y de tramar las unidades narrativas, no lo sabemos; pero queremos señalar su ocurrencia ${ }^{65}$. Se trata de que en un mismo quero el tema principal, en el modo narrativo « simple », aparece intervenido por la inclusión de pequeñas unidades narrativas visuales que parecieran corresponder a otros temas, o que han sido descritas como componentes de temáticas distintas a las de la escena principal. En el caso de la Figura $11^{66}$, se puede observar que se encuentran representados los dos episodios del enfrentamiento entre cuzqueños y antis o chunchus. Sobre un torreón con lanzas emplumadas y a un costado del mismo, un grupo de soldados inkaicos enfrenta a varios guerreros de arco y flecha, con tocados de plumas y trajes con pieles moteadas de felinos (entre los guerreros se advierten unos árboles y varias aves tropicales). El tema del vencimiento y presentación de prisioneros ocurre al otro extremo de este dibujo. Allí un soldado conduce a dos prisioneros con una soga que les amarra las manos; ellos tienen igualmente tocados de plumas y llevan loros o aves tropicales en sus hombros. El primer problema es que 

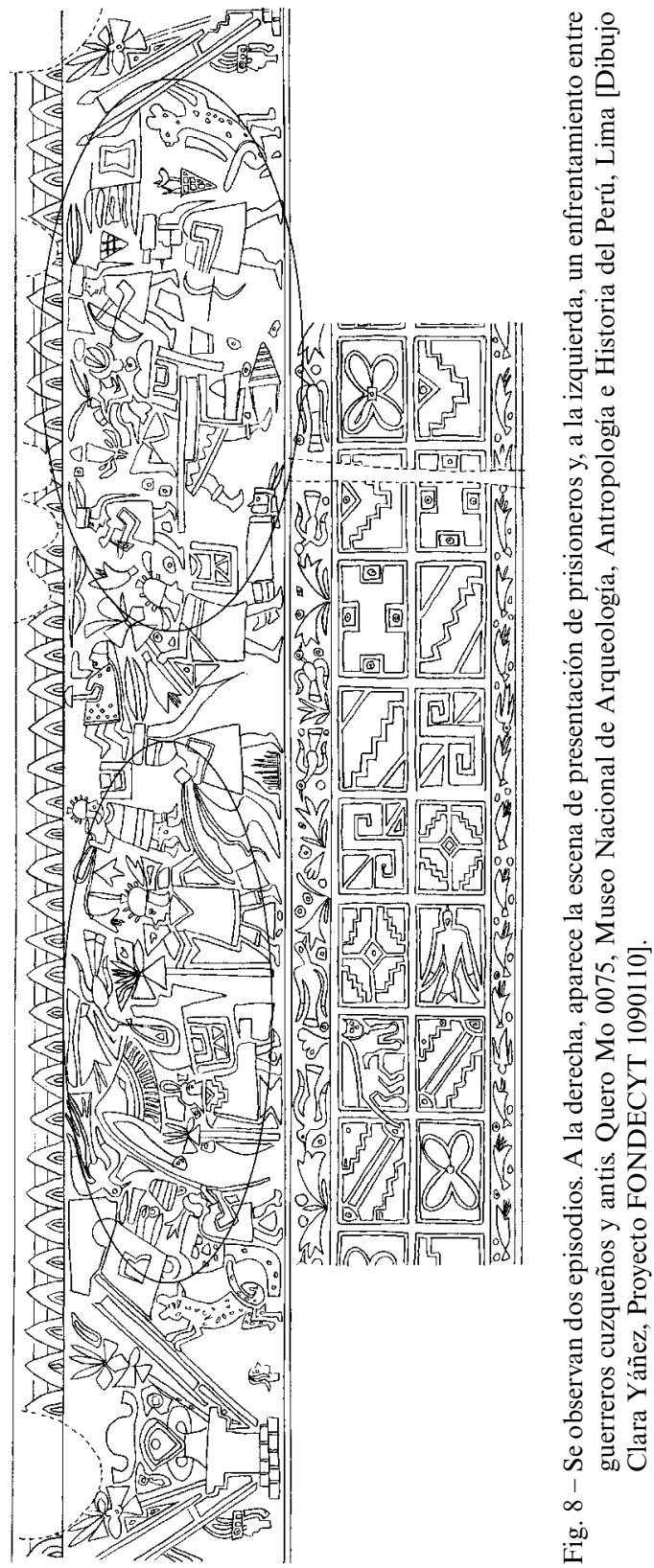


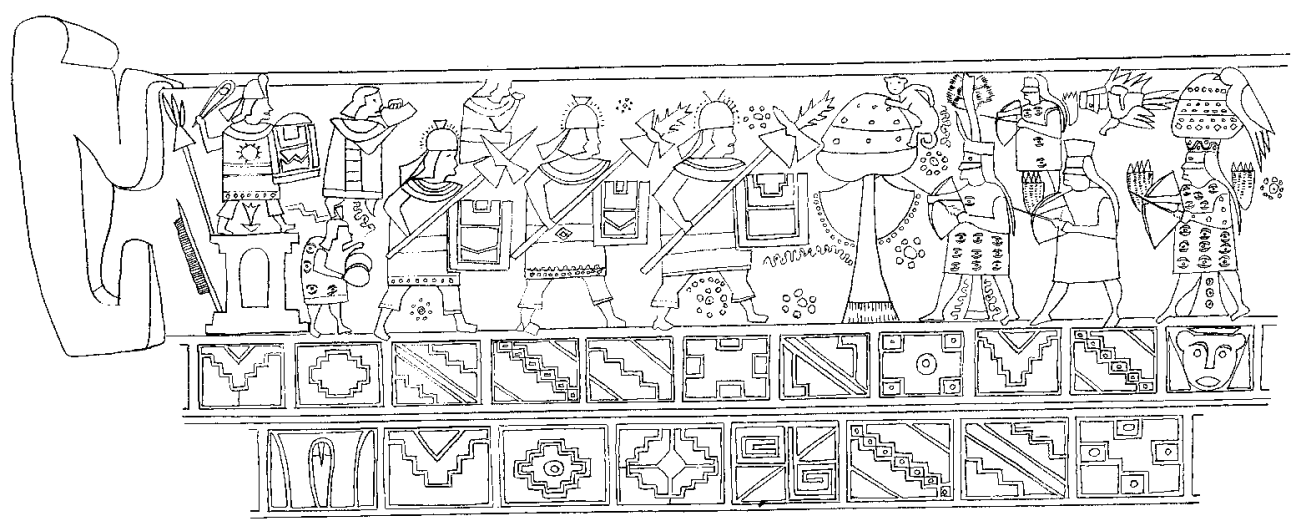

FIG. 9 - Escena de enfrentamiento entre soldados cuzqueños y guerreros chunchos o antis. Pieza 7511, Museo de América, Madrid [Dibujo Clara Yáñez, Proyecto FONDECYT 1090110, a partir del dibujo del Museo de América, Madrid].

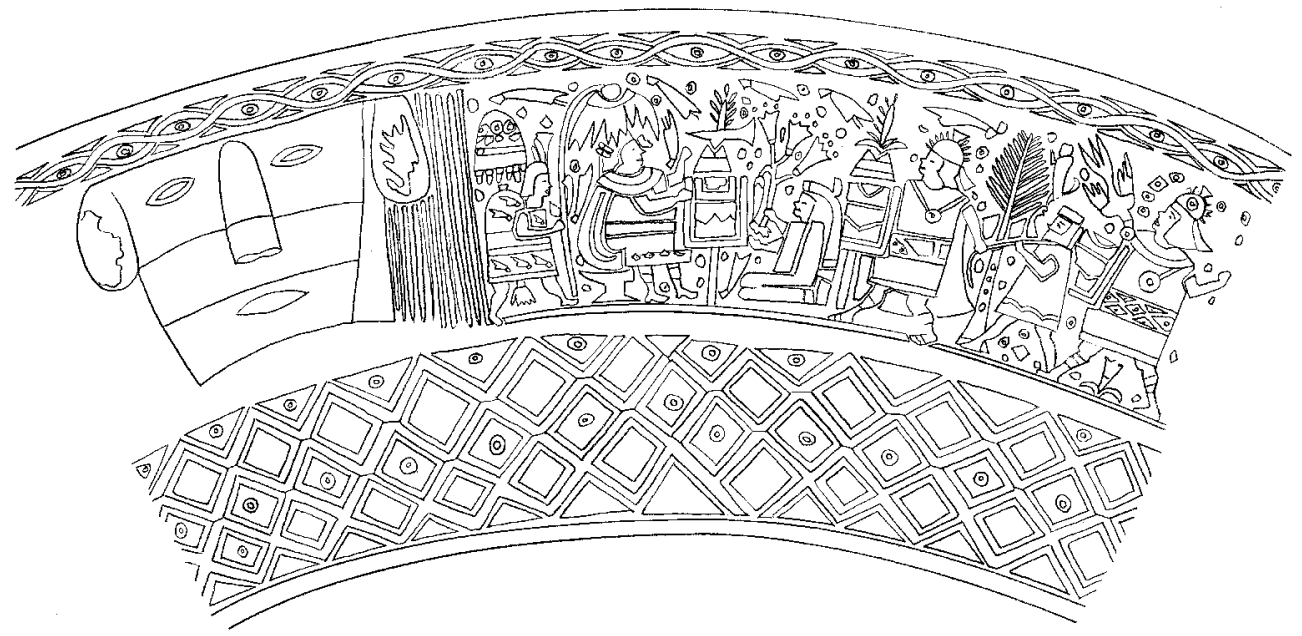

FIG. 10 - Escena de presentación : a la derecha de la escena aparece el inka sentado en su tiana y al extremo izquierdo unos soldados cuzqueños conducen a un prisionero anti atado por una cuerda a su cuello [Dibujo Clara Yáñez, de acuerdo a Posnansky 1945, plancha XLIVa, vaso procedente de la Isla del Sol]. 

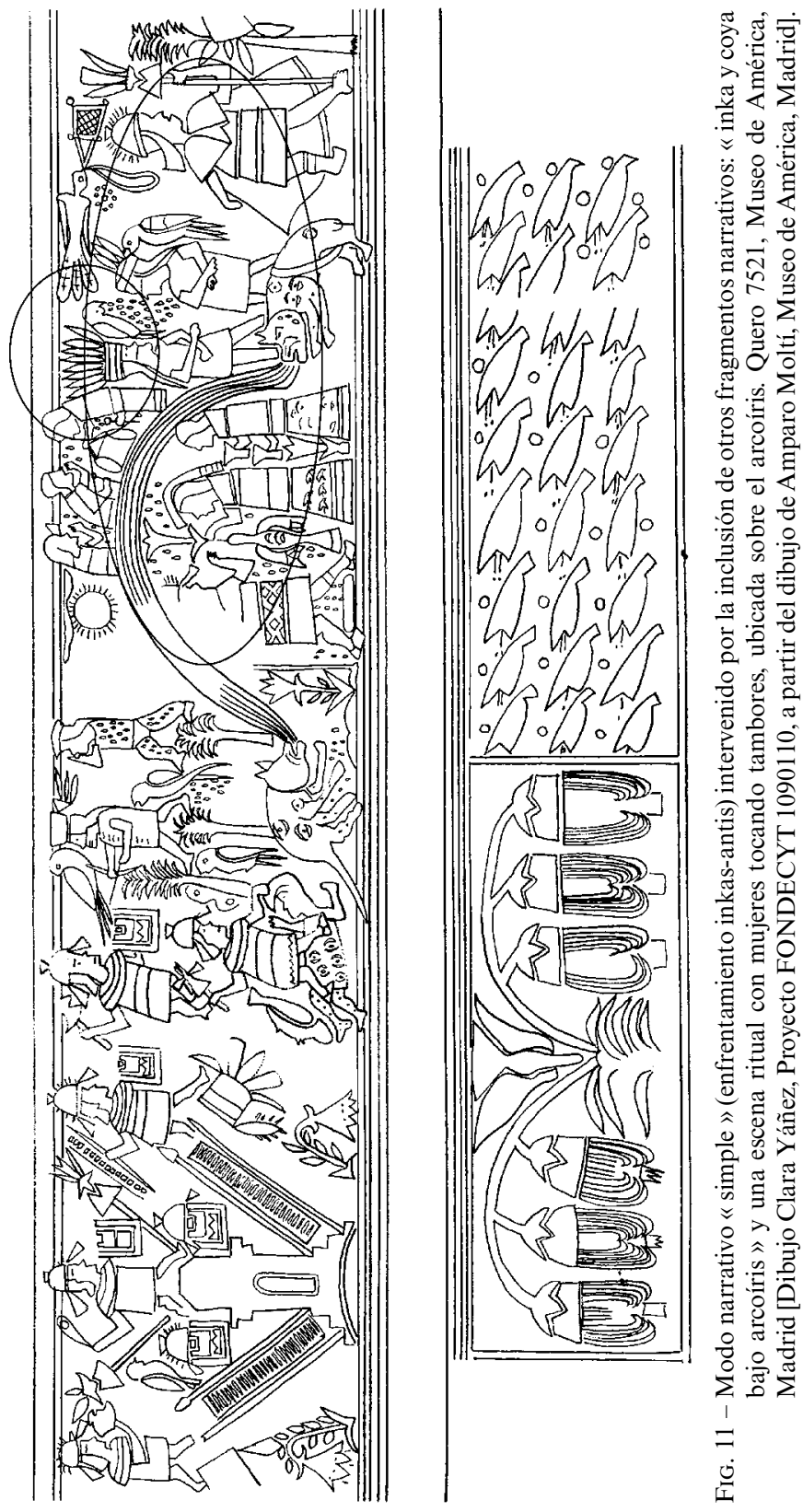
falta el resto de la escena canónica: no aparece el Inka sentado ante quien debieran ser llevados los prisioneros.

En cambio, se representó un fragmento del tema del arcoíris que conceptualmente formaba parte de otro relato. En las narrativas de las luchas contra los antis no aparecen los arcoíris e igualmente a la inversa. Además, sobre uno de los costados superiores del mismo arcoíris se ve a un grupo de tres mujeres de las cuales dos están tocando lo que parecer ser un tambor grande o un bombo que tal vez corresponda a los grandes tambores o wankar ${ }^{67}$, típicos de rituales de cantos de memoria inkaica. Definitivamente, la música, ya fuera ritual o correspondiente a alguna de las teatralizaciones de memoria que se hacían en la sociedad inkaica, no aparece en las narrativas visuales del ciclo de los enfrentamientos con los antis, y ya señalamos el enorme rigor y regularidad que tenían esas representaciones. Si bien en algunas pocas ocasiones aparece una mujer acompañando al personaje femenino principal bajo los arcoíris, no hemos visto hasta aquí el caso en que un grupo de mujeres esté tocando un tambor, ya sea dentro o a un costado de esos arcoíris. De modo que debemos concluir que se trata de fragmentos de una tercera narrativa, incluidos o incrustados aquí. Sin embargo, en los modos narrativos escritos, no hemos encontrado, hasta ahora, un equivalente de esta forma de organizar un relato.

\section{Los micro-relatos}

Se trata de la última de las variantes del modo narrativo « complejo » que hemos podido identificar. En los queros, este modo narrativo es muy claro (lo encontramos en 80 ejemplares de nuestra muestra). Presenta en una imagen muy condensada un conjunto de ocurrencias significativas que remiten a una escena de mayor desarrollo, básicamente del modo narrativo «simple ». Es lo que se puede apreciar, por ejemplo, en un vaso del Museo de América (Figura 12) ${ }^{68}$, que muestra una pequeña escena en la cual un soldado cuzqueño aparece tomando por la cabellera a un enemigo, vestido con un traje diferente al cuzqueño (sobre todo destaca su tocado), que lleva un ala en su espalda al parecer atada con unas correas que le cruzan el pecho. A la espalda del combatiente cuzqueño, un ave lleva en su pico una bolsa y una honda. Esta imagen ha sido estudiada por Ramos (2002) quien la postula como parte del ciclo mítico de la defensa del Cuzco contra la invasión de los chankas, tema al que ya nos hemos referido.

$\mathrm{Si}$ se compara este breve relato visual con el desarrollado en el quero de la Figura 13, es evidente que el primero (Figura 12) es una síntesis o micro-relato que resume lo expresado más latamente en el segundo quero (Figura 13); ambos tratan el mismo tema, pero mientras uno lo hace tomando sólo un elemento del relato, el otro muestra una escena desarrollada en modo " simple » en la cual aparecen otros personajes que completan la narración. El de la guerra entre inkas y chankas es también un tema claramente normativizado. Aunque se conocen 


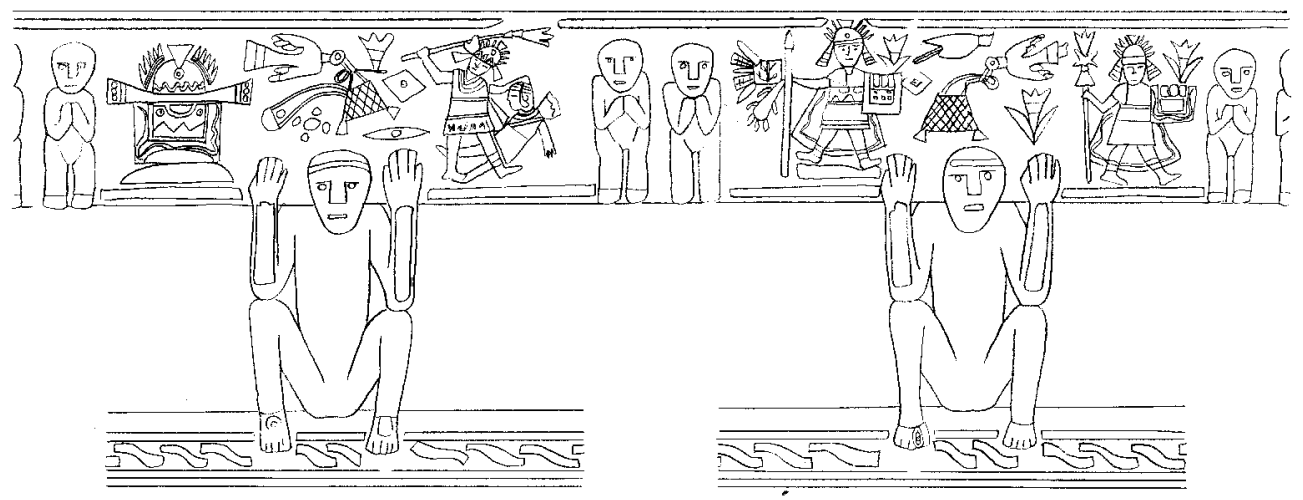

FIG. 12 - Se observa un guerrero cuzqueño sujetando por el cabello a otro combatiente, que, vestido con un traje distinto al cuzqueño, lleva unas alas en su espalda, amarradas con una doble banda sobre su pecho. Vaso 7564, Museo de América, Madrid [Dibujo Clara Yáñez, Proyecto FONDECYT 1090110, a partir del dibujo de Amparo Moltí, Museo de América, Madrid].

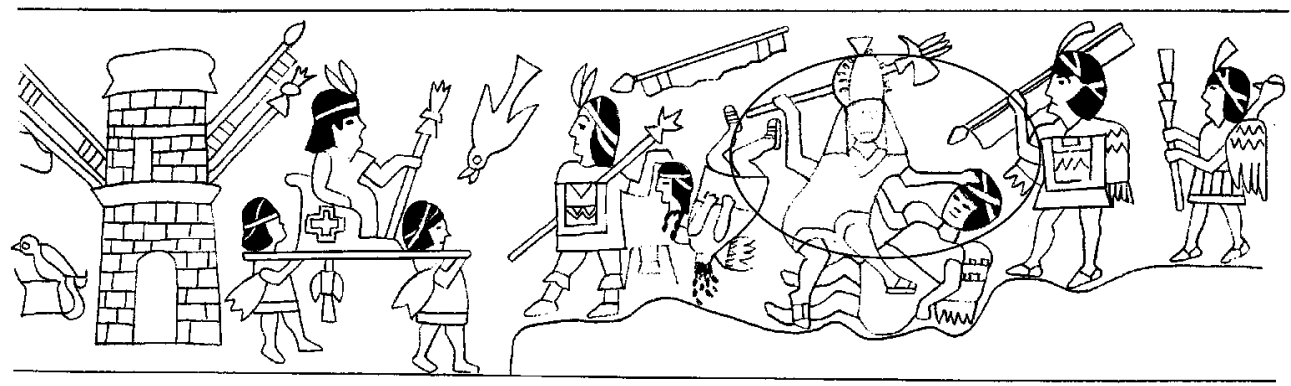

FIG. 13 - Escena del enfrentamiento entre inkas y chankas. Obsérvese que los personajes en el recuadro son los mismos que aparecen en el vaso de la Figura 12 [Dibujo Clara Yáñez, Proyecto FONDECYT 1090110, en base a Ramos 2002, figura 1].

pocos queros que lo representen ${ }^{69}$, todos ellos comparten la presentación de dos o tres conjuntos de combatientes vestidos de maneras diferentes, en los cuales un grupo está representado ya sea por aves antropomorfizadas o por guerreros que llevan alas en sus espaldas. En tres de los seis queros aparece, además, una mujer decapitando a un enemigo. Este personaje ha sido identificado como la ñusta Chañan Curi Coca, que aparece nombrada en la crónica de Pachacuti Yamqui Salcamaygua (1993 [1613?], f. 19v) y está pintada en un gran cuadro colonial ${ }^{70}$. Otro de los personajes frecuentes de este tema es un ave antropomorfizada, vestida generalmente de los colores de los trajes de los chankas. Se trata de aves 
que combaten ya sea a pie o volando y llevando en su pico hondas o bolsas con piedras para esa arma.

En el caso del ejemplo que presentamos aquí (Figura 13), al centro de la escena se encuentra la misma composición visual de un enfrentamiento entre un soldado cuzqueño y un enemigo semi-caído. En los dos casos (Figuras 12 y 13) hay un soldado cuzqueño que sostiene por la cabellera a su contrincante; en ambos, los combatientes no cuzqueños llevan un atuendo que incluye un par de alas a la espalda.

Una posible interpretación de esto es que el micro-relato mostrado en el quero de la Figura 12 formaba parte de una secuencia mayor que aparentemente podía ser relatada tanto de manera extensiva como reducida, logrando la misma comprensión de parte de quienes miraban esos vasos. La imagen reducida alcanzaría la misma eficacia simbólica que el relato extenso. ¿Estamos en presencia de un modelo de pensamiento, que permitía articular lo extenso y lo reducido, en una codificación visual fácilmente reconocible? ¿Es ésta una relación de tipo metonímico, en la que un breve fragmento o imagen permite enunciar la totalidad, o se trata de otro tipo de relación narrativa significativa?

Aquí nos parece necesario realizar una breve digresión, puesto que nuestra línea de búsqueda puede estar cruzada por una variable que no es tan evidente en los otros modos narrativos. Nos referimos a que es posible que este modo pueda ser atribuible a una tradición específica, distinta de la cuzqueña, con la cual guarda relaciones sin embargo. De los 80 ejemplares que hemos estudiado con este tipo de composición narrativa visual, 44 (55\%) están en museos de Bolivia o provienen, según los escasos registros existentes, de algunas localidades ubicadas en ese mismo país ${ }^{71}$ y es factible pensar que los restantes tengan un área de origen similar. ¿Es posible que ellos formen un conjunto con características propias, más allá de las narrativas? Esta concentración espacial principalmente en comunidades de la cuenca sur-oriental del lago Titikaka sugiere la posibilidad de que pudiéramos estar frente a formas locales de construcción de narrativas visuales diferentes a las que hemos revisado anteriormente (y que denominamos - por ahora - como «tradición cuzqueña » por ser esa el área más frecuentemente postulada como el origen de esos queros) ${ }^{72}$. Una de las características más notables de este conjunto lacustre es la alta frecuencia que tiene la representación de las escenas en el tipo de « micro-relatos » o de presentaciones «abreviadas» de temas que, en los queros de la "tradición cuzqueña », aparecen desarrollados in extenso ${ }^{73}$. Es necesario considerar por lo tanto la eventualidad de que el vaso de la Figura 12 corresponda a esa forma distinta de construcción de narrativas visuales. Se trata, efectivamente, de una manera diferente de construcción de un relato visual, porque los queros de este otro conjunto presentan además una misma estructura formal de organización de la decoración de sus superficies, en la que se combina, en el campo superior, un espacio en el que está la escena y otro en el que se incluyen figuras zoomorfas 
o fitomorfas y otras geométricas (Figura 14) ${ }^{74}$, mientras, en el campo inferior, en todos los casos, se representan dos flores alargadas en dirección izquierdaderecha, identificadas como maywa (Stenomessum incarnatum) según Liebscher (1986).
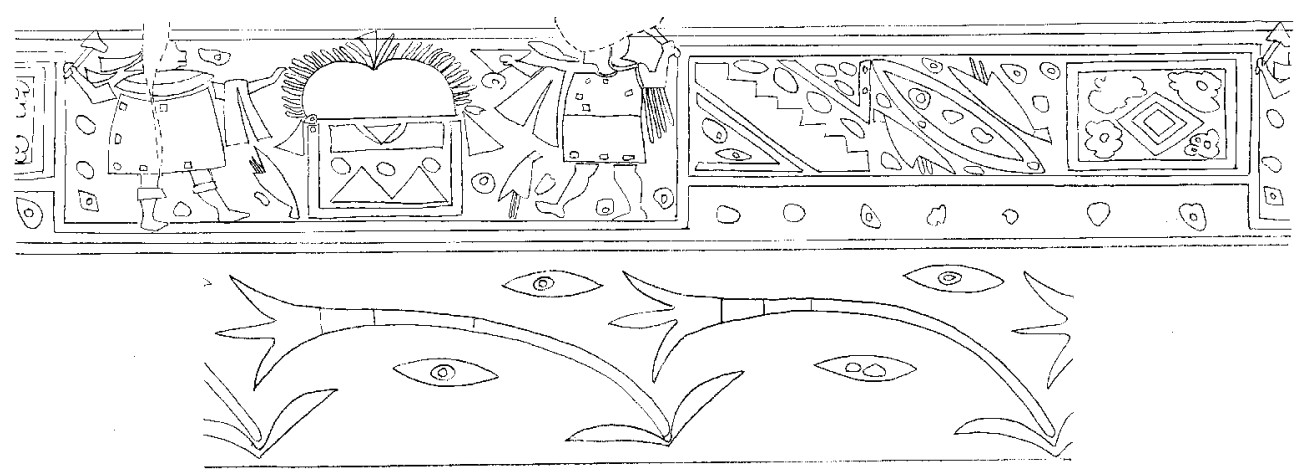

FIG. 14 - Vaso con « micro-relato » sobre el enfrentamiento entre cuzqueños y chankas (nótese el detalle del ala en la espalda de uno de los guerreros, característico de la forma de representar a los chankas en los queros coloniales). Presenta la estructura formal que organiza la mayoría de este modo narrativo, con el sub-campo lateral de rectángulos y las dos flores de maywa en la parte inferior. Quero R 14, Museo Nacional de Etnografía y Folklore, La Paz [Dibujo Clara Yáñez, Proyecto FONDECYT 1090110].

¿Estamos en presencia de una tradición local - distinta de la colonial cuzqueña - que toma los mismos temas que ésta, pero de una manera propia? Tal como lo señalamos más arriba, la mayoría de los queros que contiene este modo narrativo proviene de comunidades ubicadas en torno al lago Titikaka, por lo cual podríamos sospechar de la existencia de una tradición que llamaremos momentáneamente lacustre. ¿Son una « copia » lacustre de los relatos visuales extensos, posiblemente más apegados a una tradición colonial cuzqueña? En ambos casos, ¿A qué tipo de estructuras narrativas coloniales podría corresponder este tipo, ya sea parte de una tradición cuzqueña o de otra de carácter más lacustre?

Este tipo de relatos, reducidos a algunos elementos básicos, que apelan explícitamente a un meta-relato generalmente más extenso, parecen tener una correspondencia con un modo narrativo específico, el de los micro-relatos. Al menos en las prácticas orales andinas contemporáneas, es frecuente encontrar pequeños relatos, a veces incluso una brevísima alusión, sobre un determinado personaje, que remiten a un texto mayor, de común conocimiento de todos los interlocutores, que la mayor parte de las veces permanece no enunciado. En una pequeña localidad del sector alto del río Loa, en Inacaliri ${ }^{75}$, Mora refiere una pequeña conversación entre dos de sus anfitriones: 
- Cerca de Apacheta hay una piedra grande que siempre tiene agua, el Inca clavó su bastón ahí - dice don Damián.

- El Inca Atahuallpa es mi amigo, le voy a decir que haga llover, porque dicen que es como un dios - le responde [su interlocutor] (Mora 2010)

Sin necesidad de mayor explicación, ambos hablantes se estaban remitiendo a un ciclo narrativo mucho más extenso, el de rey Inka o Inkarri, de importante presencia en la región (Martínez C. 2008a) y uno de cuyos rasgos es, precisamente, la vara - o bastón - de rey Inka, con la cual esta divinidad podía mover cerros o piedras, o conducir el agua desde un lugar a otro. La breve conversación hace alusión a uno de los significantes nucleares del relato mayor, y con ello ya parece funcionar con eficacia significativa para la audiencia de esos habitantes de la localidad de Inacaliri. Es, creemos, precisamente éste el tipo de relación que aparece establecido en este modo de enunciación de micro-relato o de reducción de las unidades significantes a un núcleo básico de significación ${ }^{76}$.

Un proceso similar es el que se establece entre una serie de relatos del siglo XVIII, presentes en distintos tipos de soportes (música, pintura y tradición oral y escrita), esta vez en la costa norte peruana, y que aluden a la muerte del Inka Atawallpa sin necesidad de mencionarlo explícitamente. Palmiero (2011, p. 9) aborda esta problemática desde una doble perspectiva: la primera, aquella que relee la historia de la conquista española y la muerte del Inka, y la segunda, como la « persistencia de códigos andinos en la rememoración de ciertos rituales como el llanto ceremonial ». Lo interesante de su propuesta es la posibilidad de que un signo ya no lingüístico, ni visual, sino musical y un gesto ritual, den la clave interpretativa para el discurso enunciado. Así, en los siguientes versos:

Cuando la pena en el centro

Se encuentra con el sentido

Suspiro es aquel sonido

Que resulta del encuentro. (tonada El Tupacmaro, Martínez Compañón 1978 [1794], II,

f. E 188)

En los baños donde estube

Luego vine a tu llamada

Sintiendo yo tu benida

Confuso de tu llegada. (tonada La despedida, ibid., f. E 191)

Lo que postula esta autora es que « el contexto musical de las dos tonadas, esto es la escala musical, la armonía y el carácter de la melodía, vendría a ser el mismo. Las dos tonadas podrían inspirarse en el mismo modelo "compositivo", es decir, como ya se ha dicho, en el mismo tono » (Palmiero 2011, p. 18). Ese tono y el gesto ritual, el del llanto, sin hacer ninguna mención explícita al Inka o a su muerte, construyen la referencia que da significación a la canción ${ }^{77}$. Ya nos referimos más arriba a una construcción narrativa semejante en uno de los queros 
analizados aquí (véase el análisis de la Figura 1), que permitía que determinadas convenciones visuales hicieran reconocible un tema o significante, como el del « encuentro » o « desencuentro », más allá del contexto específico en el que apareciera esa construcción significante.

\section{CONCLUSIONES}

¿Cómo funcionaban los relatos andinos? Creemos que nuestra propuesta, que establece la existencia de relaciones estructurales y de pensamiento entre ciertos lenguajes visuales y orales andinos durante el período colonial, nos permite dar un paso hacia esa comprensión. Ambos tipos de relatos compartían similares procesos de construcción, ya sea acudiendo a estructuras poéticas basadas en los paralelismos semánticos, de los que los dobletes o paralelismos duplicados son el caso más claro y numeroso entre los queros, ya sea usando modos narrativos que pueden encontrarse tanto en uno como en el otro tipo de lenguajes. No estamos postulando que todos los sistemas de narración oral pueden encontrarse en las narrativas visuales coloniales de los queros, ni que éstas acudieran exclusivamente a procesos de construcción típicamente orales. Puede haber muchos más casos y complejidades. Lo que señalamos es que, en este conjunto, sí ha sido posible identificar algunos de esos procedimientos.

El uso de estructuras narrativas orales en la construcción de los relatos visuales en los queros plantea que estos eran más que la belleza de las escenas que decoraban sus superficies, mostrándonos que tenían igualmente una importante función comunicativa y que, por ello, deben ser entendidos también como textos que funcionaron dentro de la sociedad colonial andina.

Lo que queremos apuntar aquí, asimismo, es que se advierten relaciones más profundas, a nivel de estructuras organizadoras del pensamiento y de los meta-relatos, que podían ser expresados indistintamente por intermedio de diferentes sistemas de soportes y de tipos de lenguajes, corporales, táctiles, visuales $\mathrm{u}$ orales ${ }^{78}$.

La relación entre los lenguajes orales y los visuales es más compleja que la que se puede suponer inicialmente. De lo entrevisto aquí no se trataría de que los relatos visuales fueran, simplemente, una reproducción de las narrativas orales andinas, conservando los mismos personajes y sus secuencias. De nuestro análisis se desprende la existencia de un conjunto de alternativas a disposición de los enunciantes, aun para narrar un mismo tema, puesto que podían acudir a tipos simples o complejos. Esto nos lleva a preguntarnos si la intención enunciativa (o el programa semiótico) podría condicionar la selección de los procedimientos narrativos. No se trata, nuevamente, sólo de elecciones estéticas sino de intenciones comunicativas. De hecho, como lo vimos en los queros, algunas de las secuencias fueron ordenadas de una manera diferente si las comparamos con 
las versiones escritas que nos han llegado a través de los textos andinos o de las crónicas (Martínez et al. 2009).

Señalado lo anterior, nos parece altamente probable que algunas de las escenas grabadas en los queros formaran parte de tradiciones orales que podían circular a través de diferentes soportes. Esto es particularmente claro en el caso de las escenas que formaban parte de los ciclos narrativos propios a la historia del estado cuzqueño y que hemos explorado también en otros trabajos (Martínez C. 2008b, 2010; Ramos Gómez 2006, 2008). Esto no es contradictorio, sin embargo, con el plano metafórico en que esos mismos relatos pueden haber sido usados para construir nuevas connotaciones, tal como lo ha planteado Cummins (2004).

Las relaciones entre oralidades y textos escritos por andinos, por una parte, y lenguajes visuales en los queros, por la otra, tienen importantes consecuencias en lo que respecta a los estudios sobre las sociedades andinas coloniales. Abren el corpus de fuentes conocidas hasta ahora, puesto que nos entregan la posibilidad de estudiar los queros como un corpus alternativo de textos, portadores de voces andinas que funcionaron dentro del sistema colonial, aparentemente al margen de muchas de las restricciones y controles impuestos sobre lo que esas sociedades podían pensar y decir. Al menos, esos vasos no siempre fueron objeto de los mismos controles que los impuestos sobre la escritura alfabética. La posibilidad de comparar los lenguajes visuales y los orales que han quedado en los textos escritos alfabéticamente tiene también importantes consecuencias, dado que permite contrastar los tipos de enunciación orales con un tipo de fuentes independientes y alternativas; resituando, además, el peso casi exclusivo otorgado a la oralidad para el conocimiento de las sociedades andinas. *

* Manuscrit reçu en juin 2012, accepté pour publication en mai 2013.

\section{Notas}

Agradecimientos: Este trabajo es resultado del Proyecto FONDECYT 1090110. Una primera versión fue presentada en el VIII Congreso Internacional de Etnohistoria, Sucre, 2011.

Agradecemos a nuestros amigos y colegas del equipo FONDECYT, proyecto 1090110, con quienes discutimos las ideas de este trabajo y cuyos comentarios enriquecieron nuestro análisis; a Verónica Cereceda y Alan Durston por sus finos y precisos comentarios y a los pares evaluadores cuyas observaciones contribuyeron de manera notable a mejorar el manuscrito, haciéndolo más sólido. A las directoras, directores y conservadoras, así como a los funcionarios y funcionarias de los Museos de América (Madrid); Nacional de Arqueología, Antropología e Historia del Perú (Lima); Inka de la Universidad San Antonio Abad (Cuzco); Arqueológico de la Universidad Nacional de San Agustín (Arequipa); de Metales Preciosos de la Municipalidad de La Paz; Nacional de Etnografía y Folklore (La Paz); Nacional de Arqueología (La Paz); Chileno de Arte Precolombino (Santiago); National Museum of the American Indian (Smithsonian, Washington DC) y Brooklyn Museum of Art (Nueva York). Todos ellos nos permitieron estudiar sus colecciones, proporcionándonos, en muchas ocasiones, todo su apoyo para que nuestra investigación progresara. Al Museo de América, por permitirnos usar sus fotografías. 
1. Véase Itier (1992), Husson (1985, 2002), Taylor (2003), Durston (2007) y Salomon (1994) entre otros.

2. Si bien el alfabeto oficial peruano no admite las vocales $/ e /$ y $/ o /$ (deberíamos escribir qiru, entonces), parte de la bibliografía especializada se refiere a estos objetos como qero. Si nos atenemos a la grafía más común para referirnos al ayllu q’ero, debiéramos emplear una consonante glotalizada. En este trabajo emplearemos la ortografía española (quero) para evitar así los debates y problemas existentes en torno al alfabeto fonológico quechua, sobre todo en la discusión respecto del pentavocalismo versus trivocalismo y de las consonantes glotalizadas o aspiradas, ambos aspectos presentes en las posibles grafías q'erolqero, y qerolqiru.

3. Para este trabajo estudiamos un universo de 553 queros, de los cuales 367 son del período colonial y su producción abarca desde mediados del siglo XVI hasta inicios del siglo xIx. Pudimos estudiar directamente 504 ejemplares, depositados en diez museos. La lista completa se encuentra más arriba. Los restantes 186 queros son prehispánicos. No los incluimos en este estudio ya que recién hemos iniciado su análisis.

4. El primero de ellos fue el virrey Francisco de Toledo, quien llevó varios queros a Carlos V, además de otros para su colección privada (Julien 1999). También se pueden mencionar al obispo Martínez Compañón y al virrey Amat, ambos en el siglo XVIII (Cabello Carro 1994).

5. Sobre la belleza de los queros y el placer estético que podían provocar, véase el fino análisis de Cummins (2004, p. 255 ss.), con el que coincidimos plenamente.

6. Aunque se conoce al menos un ejemplar producido en el siglo XIX, que representa a un soldado republicano de las guerras por la Independencia, pisando victorioso a un español vencido (Flores Ochoa et al. 1998, p. 271), no existen estudios sistemáticos sobre la producción de queros a partir del siglo xIx. Actualmente se puede identificar una producción campesina, anónima, de vasos rituales de madera, que pueden variar de forma y tamaño, y que no tienen decoración en su superficie; y otra, hecha por artesanos, en la que esos objetos pueden incluso estar firmados, y que reproduce de manera libre la tradición colonial, estando más orientada a la comercialización que al uso ritual (véanse, por ejemplo, algunos ejemplares existentes en el Museo Inka, de la ciudad del Cuzco, y en las colecciones del National Museum of the American Indian, en Washington). Hay registros documentales y etnográficos que señalan que en algunas comunidades andinas aún se continúa utilizando estos vasos, ya sea prehispánicos o coloniales, para diversos rituales comunitarios.

7. Aunque su producción se extendió a lo largo de todo el período colonial, los temas y las modalidades de su representación fueron diferentes, vinculados a los cambios político-sociales vividos por las poblaciones andinas (Martínez C. 2012). Durante el gobierno del virrey Francisco de Toledo (1569-1581), se desarrolló una campaña contra las imágenes andinas, consideradas idolátricas, lo que afectó a los queros que circulaban en esa época y que tenían decoraciones abstractas o de animales e insectos. En los queros posteriores a Toledo se desarrollaron sobre todo las narraciones con escenas del tipo que analizamos aquí.

8. Durante el período prehispánico, la madera más utilizada parece haber sido del árbol conocido como chachacoma (del género Escallonia); durante el período colonial los ejemplares analizados han mostrado una preponderancia de algarrobo (Prosopis), aunque también se encuentran ejemplares hechos con chachacoma (Kaplan et al. 1999).

9. En lo que sigue, la mayoría de nuestros ejemplos de queros provienen de esta «tradición cuzqueña ». Más adelante explicitaremos cuando incorporamos otros queros diferentes a este centro de producción y circulación colonial.

10. En una ponencia presentada en el $54^{\circ}$ Congreso Internacional de Americanistas (Viena 2012), Ana María Presta estudió testamentos indígenas de la ciudad de La Plata, hoy Sucre, apuntando que muchos indígenas aparecían en posesión de estos vasos coloniales, lo que refuerza el dato proporcionado por Vázquez de Espinoza.

11. Ante la dificultad de obtener fechados absolutos para cada ejemplar, las cronologías propuestas por distintos autores han sido elaboradas básicamente por la identificación de diferencias de estilos («formal» o « libre» en el caso de Rowe 1961), por asociación corológica (una práctica 
arqueológica que busca similitudes con motivos que sí pueden ser fechados, como una determinada moda, por ejemplo) o temática (la ya referida al tema de la Independencia, u otra). Recientemente, gracias a un trabajo de análisis de los tipos de pigmentos usados en la decoración de los queros, en especial los distintos pigmentos blancos, se ha podido proponer una cronología más ajustada (Howe et al. 2013). En el caso del quero que presentamos aquí, su datación más probable es del siglo XVII.

12. La composición visual de los guerreros cuzqueños es bastante canónica y distintiva; aparece tanto en los queros como en muchas de las láminas de Guaman Poma y en algunos cuadros cuzqueños de los siglos XVII y XVIII. El traje de esos personajes está compuesto básicamente por una camisa larga, o unku (que puede incluso tener una decoración en la cintura o en el borde inferior) y por el casco, o chucu, de forma semicircular y que tiene a veces plumas en su parte superior. Las armas de esos soldados son un escudo, o pullqana, y una lanza (chuqui o chuquichambi) o una honda (waraq'a) para arrojar piedras.

13. Las convenciones visuales de la época, presentes también en las láminas de Guaman Poma, sitúan al espectador como si éste estuviese dentro del cuadro y no enfrentado a él (Cereceda 1987, p. 150), de modo que la lectura de las posiciones representadas debe hacerse desde ese punto de observación, en un orden espejado. De esta manera, la derecha del espectador corresponde a la izquierda de la escena y viceversa.

14. A espaldas del primero hay un árbol frondoso que no hemos podido identificar y, entre ambos, hay una palmera o chonta de la cual se identifica con facilidad una de sus hojas.

15. Sobre el proceso de identificación de las distintas unidades significativas que componen estas escenas véase Martínez et al. (2009).

16. En este caso, se identifica al inka por ser una autoridad que es llevada en andas (wantu o rampa), sobre los hombros de unos sirvientes y por llevar en su frente una pluma de una ave conocida como corequenque (o carancho andino), que sólo el Zapan Inka podía llevar. La configuración de la imagen de la autoridad se completa con su presentación como un personaje sentado, atributo específico de las autoridades andinas.

17. La superficie decorada del vaso se completa con una banda estrecha que tiene una serie de objetos lenticulares y un campo inferior, con dos bandas horizontales de ñuqchu (Salvia sp., Salvia biflora, también Fuchsia boliviana). No las incluimos en nuestro análisis porque se apartan del objeto del trabajo que presentamos aquí. En la identificación de las especies de flores, seguimos a Liebscher (1986).

18. Por popular nos referimos a que se trata de uno de los temas más representados o de los que se conocen actualmente más queros. Cummins (1988, p. 34) lo describe como el tercero en número de ejemplares de su muestra. En nuestra muestra, de 367 vasos coloniales considerados para este estudio, pudimos identificarlo en 35 ejemplares (un 9,5\%), lo que representa una frecuencia muy alta.

19. En otros queros, este conjunto significante básico, se amplía a monos y aves tropicales; pero continúa recurriendo a un número acotado de significantes visuales.

20. Recordemos que estos conjuntos visuales circularon desde finales del siglo XVI (véase la nota 7), pero su uso se extendió al menos hasta el siglo XVIII.

21. Gisbert 1980, fig. 28. Estas escenas también han sido tratadas como la representación del encuentro entre Incarí y Collarí (personajes que corresponden al Inka y al señor de los collas del altiplano andino en las narraciones coloniales y contemporáneas, Cummins 2004, pp. 335-343), como el encuentro entre dos grupos distintos de cuzqueños (Ziółkowski et al. 2008, figuras 1 y 2), o como parte de una escena de rituales de agricultura y fertilidad (Liebscher 1986, p. 32 ss.).

22. Cummins 2004, p. 335 ss. Para este autor, en una lectura de nuevos posicionamientos de los espacios coloniales, el tema del encuentro entre el Inka y el Hatun Qolla envuelve una situación de tensión y de rivalidad entre ambos grupos.

23. Ziółkowski et al. (2008) han interpretado algunas de estas escenas como parte de los ciclos de enfrentamientos entre inkas.

24. Más adelante retomaremos esta idea, porque una y otra solución no son necesariamente opuestas, sino que, nos parece, pueden estar reflejando dos propuestas distintas pero intrínsecamente vinculadas. 
25. "Quirocamayoc » fue el término empleado por el cronista andino Guaman Poma para referirse a los carpinteros o artesanos de la madera. El mismo autor señala, sin embargo y a continuación, que los encargados de la decoración de los queros y mates (otro tipo de vasos) eran denominados «llinpec »: « decorador[es] en lacre » (Guaman Poma 2004 [1616], f. 191 [193]), aludiendo ya sea a la sustancia empleada para rellenar las figuras de los vasos, o al color rojo de ese material. Llimpikuna era, en otro diccionario colonial, el de González Holguín, « Todas las maneras de colores del lacre con que pintan vasos de madera » (1989 [1608], p. 213). Por esto, preferimos el uso de llimpikamayoq (con una traducción aproximada de «los que saben usar el llimpi») para referirnos a los especialistas en la decoración de los queros.

26. Como hemos señalado, esto corresponde a la izquierda del observador.

27. Martínez S. 2010.

28. Si se sigue el relato de las teatralizaciones hechas por los indígenas en Potosí en 1555, entre ellas estaba la representación de la victoria inkaica sobre los chankas (Arzáns de Orsúa y Vela 1965 [1735], libro IV, cap. I, p. 95 ss.).

29. Probablemente en este sentido sea sugerente tener en mente el concepto de meta-relato. Según nuestro modo de entender, la diferencia entre una macrosemiótica y un meta-relato radica en la perspectiva de análisis. Mientras la primera apunta a la multiplicidad de soportes y sus mecanismos inherentes de referencia y de significación, el segundo, a partir de la propuesta de Cereceda (1993, p. 229), establece que « distintos textos remiten los unos a los otros y que esas conexiones constituyen a su vez un texto aparte, un nuevo mito no narrado, pero presente en el espíritu de aquellos que dominan el conjunto de estos relatos » [traducción de los autores].

30. De acuerdo a su temática (uno de los ciclos de memoria colonial sobre el pasado inkaico) y por el estilo « libre » (sensu Rowe 1961), este quero de autor anónimo puede ser fechado como del siglo XVII o inicios del XVIII.

31. El baile de la soga se ha ilustrado también en una pintura colonial que representa el funeral de Huáscar (véase Gisbert 1980).

32. El artículo que citamos, « El juego de los ayllus y del amaru » [1967], fue reeditado en 1989 junto a otros trabajos del autor.

33. Husson (2002, p. 392) se refiere a esta característica como la principal que nos permite dilucidar la estructura del género poético y que se identifica como « una misma estructura sintáctica, de modo que a cada vocablo de la una corresponde un vocablo homólogo en la otra. En segundo lugar, considerando los términos homólogos que difieren - los hay que son idénticos -, diremos que forman un doblete. Ahora bien, además de pertenecer a la misma categoría gramatical - consecuencia de la identidad de estructura sintáctica -, los elementos constitutivos de un doblete siempre presentan cierta afinidad a nivel semántico ».

34. Cursivas y negritas de los autores, para marcar ambas variantes. El texto original está en quechua y no tiene la estructura versificada que aquí ponemos para mayor claridad de la lectura. La traducción del original quechua de Guaman Poma es la de G. Urioste publicada en la edición citada.

35. Cummins lo describió como el segundo conjunto más importante por su representatividad en la muestra que el usó para su investigación en 1988 (Cummins 1988, p. 32). Se trata de un motivo importante, también, porque al parecer empezó a representarse a partir de la segunda mitad del siglo XVI y siguió haciéndose, con pocas variantes, probablemente hasta avanzado el siglo XVIII (Martínez C. 2012).

36. 20 casos de un total de 55 queros que tienen este motivo en nuestra muestra.

37. 18 casos del total de 55 ya mencionado.

38. En estos casos, la representatividad es de tres ejemplares para cada uno de ellos. Hay otras posibilidades, pero todas con muy baja representatividad, generalmente de un único caso: mujer/amaru, hombre cazador/amaru, mujer/ escudo, sirena/sirena.

39. Hasta el momento hemos podido identificar 29 ejemplares de queros en los que ocurre esta forma de enunciación, un $52,7 \%$ del conjunto. 
40. Por su estilo « formal » o rígido, con figuras en posición frontal (Rowe 1961) y por la técnica de ejecución, este quero puede haber sido confeccionado a finales del siglo XVI.

41. Por su técnica mixta, de figuras incisas-grabadas (los cuadrados concéntricos del campo intermedio) y de inciso areal relleno con pigmentos de colores, este vaso parece ser de la segunda mitad del siglo XVI, posiblemente anterior al arribo del virrey Francisco de Toledo a los Andes, o contemporáneo a ese período.

42. Se trata de un largo trozo de tela que envuelve, tubularmente, el cuerpo de una mujer y es sostenido por dos largos alfileres en la parte superior.

43. En la identificación de las especies de flores, seguimos a Liebscher (1986).

44. El nombre de amaru sirve para nombrar varias manifestaciones de las grandes serpientes en los Andes, ya se trate de aquellas de gran tamaño que habitaban en los espacios selváticos y que eran reconocidas como divinidades por los habitantes del Antisuyu o porción oriental del Tawantinsuyu (Guaman Poma 1615, f. 269 [271]) o de una serpiente mítica, a veces de gran tamaño o monstruosidad, que podía provocar una enorme destrucción. En algunas fuentes coloniales aparece como un animal alado y con patas (Pachacuti Yamqui Salcamaygua 1993 [1613?], f. 21v) de ahí la identificación que se hace de ella para el caso del quero Mo 10395.

45. A mayor abundamiento, eran algunos de esos gobernantes los que portaban su nombre, como el hijo de Inka Ruqa, Uturunqu Achachi Amaru Inka que fue uno de los conquistadores de las tierras de los antis (Guaman Poma 1615, f. 154 [156]).

46. Véase el análisis hecho por Curatola y de la Puente (2013).

47. Agradecemos a Alan Durston habernos llamado la atención al respecto.

48. Recordemos que para este trabajo analizamos una muestra de 553 queros, de los cuales 367 son coloniales. En 271 de esos queros coloniales $(73,8 \%)$ se puede identificar una narración; el resto, $96(26,1 \%)$, presenta figuras aisladas o en series en las que no es posible identificar - hasta ahora - una narrativa específica.

49. La versificación es de Fossa (2005, p. 41). Es necesario aclarar que el texto que versifica Fossa no es exactamente el del original de Betanzos. Nosotros hemos respetado el original.

50. Este modo narrativo está presente en 77 de los 271 queros en los que hemos identificado narrativas coloniales.

51. La datación probable de este quero es de la primera mitad del siglo XVIII.

52. Conocemos al menos 8 ejemplares con esta estructura narrativa, véase, por ejemplo, la pieza VA 38404 del Museum für Völkerkunde de Berlín, en Wichrowska y Ziółkowski 2000.

53. Agradecemos nuevamente a Alan Durston habernos llamado la atención en este punto.

54. En este caso, se trata de una copa que posee las mismas características técnicas y decorativas que los otros queros presentados en este trabajo, y de acuerdo a Flores Ochoa et al. (1998) correspondería a formas que son tardías, del siglo XVIII.

55. Taylor 1987, cap. I: 15, p. 49; cap. xv: 1, p. 253. Cursivas de los autores. Para mayor claridad de los lectores no familiarizados con este tema, la respuesta de los redactores andinos del texto de Huarochirí, equivale a que un cristiano de la época señalara no saber si el Apocalipsis era antes o después del Génesis. O no poder indicar si los europeos estaban antes o después que los andinos, ya que cada una de las divinidades andinas mencionadas en la cita representaba una humanidad distinta. Tal como lo han señalado Bouysse-Cassagne y Harris (1987), los tiempos andinos - pasado y presente son coexistentes y coetáneos, y no excluyentes y sucesivos como ocurre en el pensamiento cristiano europeo de la época.

56. Para una discusión más detallada de la coexistencia de pacha o tiempos/espacios en el pensamiento andino (de pasado y presente, en nuestros términos), véase Bouysse-Cassagne y Harris 1987.

57. "Los hombres de la edad Wari Wira Qucha», «los hombres Wari Runa», "gente de la edad del Purun », respectivamente, en la traducción de Rolena Adorno que acompaña a esa edición digital.

58. Sobre construcciones narrativas europeas durante el período colonial, en las cuales se entrelazan o entrecruzan diversas temporalidades y temáticas, véase el análisis hecho en Martínez C. 2011. 
59. Véase Sarmiento de Gamboa (2001 [1572], caps. XxvII ss.), Cabello Valboa (1951 [1586], caps. XIV y XV) o Cieza de León (1986 [1550], caps. XLIV-XLVII, pp. 129-139), Garcilaso de la Vega (1991 [1609], libro IV, caps. Xv, XXI-XxIV y libro V, caps. XVII-XXIV, XXVI, tomo I, pp. 228-231, 242-249, 289-310, 314-315).

60. Como ya señalamos, se trata de 35 ejemplares. Este episodio ha sido denominado «motivo batalla » por Cummins (1988, p. 34). Liebscher (1986) y Flores Ochoa et al. (1998) no establecen un motivo específico para el enfrentamiento entre cuzqueños y antis o chunchus, limitándose a incluir en los « enfrentamientos » $\mathrm{o}$ « motivos bélicos » todas las escenas de este tipo.

61. Descrito también como « motivo presentación » por Cummins. Para un análisis de un posible significado de estas escenas y tema, véase Cummins (2004, p. 354 ss.).

62. Tenemos identificados dos ejemplares en los que ambos episodios aparecen en un mismo vaso: la pieza Mo 0075 del Museo Nacional de Arqueología, Antropología e Historia del Perú (Lima) y Posnansky (1945, lámina XLIVc).

63. Para el episodio del enfrentamiento o « batallas », conocemos 19 ejemplares y para el denominado «presentación de prisioneros », tenemos registrados 10 vasos.

64. Por el tallado en relieve de un felino, el quero de la Figura 9 parece ser de elaboración más temprana (siglo XVII) que el de la Figura 10, más propio del estilo decorativo y de algunas técnicas usadas en el siglo XVIII.

65. Hemos identificado, hasta ahora, tres ejemplares con estas características. Se trata de los queros 7521, 7527 y 7572, todos del Museo de América (Madrid).

66. Por sus características formales, con una banda central en relieve, y estilísticas (obsérvese el movimiento de algunos de los personajes), este ejemplar podría ser de finales del siglo XVII o de la primera mitad del siglo XviII.

67. En el diccionario quechua de González Holguín aparece la siguiente voz: « Huancarhuayñu: mujer muy uamborilera [tamborilera] amiga de tocar» (1989 [1608], primera parte).

68. Su forma, ya alejada de aquella más clásica y conocida, la troncocónica, permite ubicar esta pieza como perteneciente al siglo XVIII.

69. Ramos (2002) publica cuatro ejemplares y Flores Ochoa et al. (1998) agregan uno adicional, proveniente del Museo Nacional de Arqueología de Bolivia. En el Museo de Etnografía de Bolivia, pudimos identificar otro ejemplar con el mismo tema (Musef $\mathrm{R}$ 14), precisamente en una versión reducida de la misma narración (Figura 14).

70. Véanse los trabajos de Ramos Gómez $(2001,2002)$ y Martínez C. (2011).

71. Los 18 queros del Museum für Völkerkunde de Berlín provienen principalmente de las localidades Escoma, Carabuco y Sampaya, todas en el borde oriental del lago Titikaka, en tanto que varios de los 10 existentes en el Museo de Metales Preciosos de La Paz, tienen registro de procedencia de Tiwanaku. De los 12 que se guardan en el Museo Nacional de Arqueología de Bolivia, sólo algunos tienen registro de procedencia, y figuran como parte de la colección Posnansky, quien trabajó fundamentalmente en el borde oriental del lago Titikaka, también en el actual lado boliviano. En los museos peruanos la presencia de este tipo de queros es más bien escasa, no pasando de tres o cuatro ejemplares por museo. Algo similar ocurre con algunos museos de Estados Unidos, que igualmente poseen pocos ejemplares de este tipo (National Museum of the American Indian, American Museum of Natural History y Brooklyn Museum of Art).

72. Flores Ochoa et al. (1997) ya postularon la existencia de un conjunto de vasos que podrían ser parte de tradiciones coloniales aymaras, en las que predominarían escenas lacustres, con sirenas, peces y representaciones del mismo lago Titikaka, por lo que no es una novedad plantear aquí su existencia. La tradición postulada por esos autores, sin embargo, es de orden temática. Para ellos, habría un determinado conjunto de temas más o menos propios del mundo aymara lacustre.

73. Decimos alta frecuencia porque entre los queros provenientes de localidades como Zampaya o Coatí (ambas en Bolivia), también pueden encontrarse queros con otros tipos de representaciones (véase el quero VA 11808 del Museum für Völkerkunde, de Berlín). 
74. Ziółkowski (2000, p. 126) identifica algunos de ellos como similares a algunos de los tocapus (o t'uqapu) identificados por Victoria de la Jara, aunque de una factura técnica y composicional de menor calidad que los cuzqueños. De la Jara postuló que esos tocapus (signos visuales, abstractos, de forma generalmente cuadrada) constituían una forma de escritura inka.

75. Ubicada en el norte de Chile, en la actual II Región de Antofagasta.

76. No postulamos, con esto, que esa sea una manera culturalmente singular de narrar, propia únicamente a las culturas andinas. Es bastante frecuente encontrar ese tipo de referencias a relatos mayores también en ciclos narrativos de culturas como la europea medieval u otras.

77. Tal como señaló correctamente uno de los evaluadores de este artículo, este ejemplo ilustra muy claramente que el tipo de relación entre los modos expresivos va más allá de la redundancia (aunque traten de meta-relatos comunes).

78. En un reciente trabajo, Fossa (2011) ha planteado la existencia de relaciones similares entre los quipus y las oralidades andinas. Y Cummins planteó la existencia de un tipo de relaciones sintácticas entre los queros y los textiles cuzqueños prehispánicos (2007, p. 276).

\section{REFERENCIAS CITADAS}

ArzÁNS de Orsúa y Vela Bartolomé

1965 Historia de la Villa Imperial de Potosí, tomo I, edición y estudio preliminar de Lewis Hanke y Gunnar Mendoza, Brown University Press, Providence [1735].

Betanzos Juan de

1987 Suma y narración de los incas, edición de María del Carmen Martín Rubio, Eds. Atlas, Madrid [1551].

Bouysse-Cassagne Thérèse y Olivia Harris

1987 «Pacha: en torno al pensamiento aymara », in Thérèse Bouysse-Cassagne, Olivia Harris, Tristan Platt y Verónica Cereceda, Tres reflexiones sobre el pensamiento andino, HISBOL, La Paz, pp. 11-60.

Cabello Carro Paz

1994 «Los inventarios de objetos incas pertenecientes a Carlos V: estudio de la colección, traducción y transcripción de los documentos », Anales del Museo de América, 2, pp. 33-61.

Cabello Valboa Miguel

1951 Miscelánea antártica. Una historia del Perú antiguo, Universidad Nacional Mayor de San Marcos, Lima [1586].

Cereceda Verónica

1987 «Aproximaciones a una estética andina: de la belleza al tinku », in Thérèse Bouysse-Cassagne, Olivia Harris, Tristan Platt y Verónica Cereceda, Tres reflexiones sobre el pensamiento andino, HISBOL, La Paz, pp. 133-231.

1993 "Cette étendue entre l'Altiplano et la mer... Un mythe chipaya hors texte », in Aurore Monod-Becquelin y Antoinette Molinié (eds), Mémoire de la tradition, Société d'ethnologie, Nanterre, pp. 227-284. 
Cieza De León Pedro

1986 Crónica del Perú. Segunda parte, Pontificia Universidad Católica del Perú/Academia Nacional de Historia, Lima [1550].

Cummins Thomas B. F.

1988 Abstraction to narration: Kero imagery of Peru and the colonial alteration of native identity, tesis de doctorado, UMI Dissertation Services, Ann Arbor, Michigan.

2004 Brindis con el Inca: la abstracción andina y las imágenes coloniales de los queros, Fondo Editorial UNMSM/Embajada de los Estados Unidos de América/Universidad Mayor de San Andrés, col. « Coediciones », Lima. «Queros, aquillas, uncus and chulpas: The composition of Inka artistic expression and power », in Richard Burger, Craig Morris y Ramiro Matos M. (eds), Variations in the expression of Inka power, Dumbarton Oaks, Harvard University Press, Washington DC, pp. 267-311.

Curatola Marco y José Carlos de la Puente

2013 «Contar concertando: quipus, piedritas y escritura en los Andes coloniales », in Marco Curatola y José Carlos de la Puente (eds), El quipu colonial. Estudios y materiales, Pontificia Universidad Católica del Perú, Lima, pp. 193-243.

Del Río Mercedes

2010 "Los tesoros de los mallku de Pocona y Totora en el siglo XVI », Chungara, 42 (1), pp. 199-220.

Durston Alan

2007 Pastoral Quechua. The history of christian translation in colonial Peru, 1550-1650, University of Notre Dame Press, Notre Dame.

Flores OchOA Jorge, Elizabeth KuON y Roberto Samanez

1997 "Vasos de madera. Región del lago Titicaca », Arkinka, 25, pp. 102-111.

1998 Qeros. Arte inka en vasos ceremoniales, Banco de Crédito del Perú, col. « Familiar Arte y Tesoros », Lima.

Fossa Lydia

2005 «Desde que florecía como flor de huerto: el cantar de Inca Yupanqui en la Suma y narración de Juan de Betanzos », in Jean-Philippe Husson (ed.), Entre tradición e innovación. Cinco siglos de literatura amerindia, Pontificia Universidad Católica del Perú, Lima, pp. 27-48.

2011 "Khipu y discurso: paralelismos en el mundo andino », in Liliana Regalado y Francisco Hernández, Sobre los Incas, Instituto Riva-Agüero, Lima, pp. 89-127.

Garcilaso de la Vega Inca

1991 Comentarios Reales de los Incas, edición a cargo de Carlos Araníbar, Fondo de Cultura Económica, México, 2 vol. [1609].

GisBeRt Teresa

$1980 \quad$ Iconografía y mitos indígenas en el arte, Gisbert y C. ${ }^{\text {ia }}$, La Paz. 


\section{GonzÁLEz Holguín Diego}

1989 Vocabulario de la lengua general de todo el Perú llamada lengua qquichua o del inca..., edición facsimilar de la edición de 1952, Universidad Nacional Mayor de San Marcos, Lima [1608].

Guaman Poma de Ayala Felipe

2004 El primer nueva corónica i buen gobierno, publicado en facsímil digital por el Royal Library, Copenhage [www.kb.dk/permalink/2006/poma/info/en/ frontpage.htm] [1616].

Howe Ellen, Emily Kaplan, Tony Frantz, Ellen Pearlstein, Judith Levinson, Richard Newman y Odile MadDEN

2013 "Estudio técnico de keros inka y post-inka », ponencia presentada en el XIX Congreso nacional de arqueología chilena, Arica.

Husson Jean-Philippe

1985 La poésie quechua dans la chronique de Felipe Waman Puma de Ayala. De l'art lyrique de cour aux chants et danses populaires, L'Harmattan, París.

2002 «Literatura quechua », Boletín del Instituto Riva-Agüero, 29, pp. 387-522.

ITIER César

1992 «La tradición oral quechua antigua en los procesos de idolatrías de Cajatambo », Bulletin de l'Institut français d'études andines, 21 (3), pp. 1009-1051.

JULIEN Catherine

1999 «History and art in translation: the paños and other objects collected by Francisco de Toledo », Colonial Latin American Review, 8 (1), pp. 61-89.

Kaplan Emily, Ellen Pearlstein, Ellen Howe y Judith Levinson

1999 "Qero. Análisis técnico de los qeros pintados de los períodos inca y colonial », Iconos. Revista peruana de conservación, arte y arqueología, 2, pp. 30-38.

LIEBSCHER Verena

1986 La iconografía de los qeros, Herrera Editores, Lima.

MANHEIM Bruce

1991 The language of the Inka since the European invasion, University of Texas Press, Texas Linguistics Series, Austin.

MarTínez Rosalía

2009 «Musiques, mouvements, couleurs dans la performance musicale andine. Exemples boliviens », Terrain, 53, pp. 84-97.

MarTínez COMPaÑón Baltazar

1978 Trujillo del Perú, Ediciones Cultura Hispánica del Centro Iberoamericano de Cooperación, Madrid [1794].

Martínez C. José Luis

2008a "Nous sommes un reste de gentils" : le maniement du temps et la construction des différences au sein de trois communautés andines 
(Chili) ", in Anath Ariel de Vidas (ed.), Jeux de mémoires - enjeux d'identités. Pour une histoire souterraine des Amériques. Mélanges offerts à Nathan Wachtel, L'Harmattan, París, pp. 101-124.

2008 b «Pensarse y representarse. Aproximaciones a algunas prácticas coloniales andinas de los siglos XVI y XVII », in Paola González y Tamara Bray (eds), Lenguajes visuales de los Incas, BAR International Series 1848, Oxford, pp. 147-161.

2010 " "Mandó pintar dos aves...": relatos orales y representaciones visuales andinas ", Chungara, 42 (1), pp. 157-167.

2011 «Cómo recordar? La construcción de las memorias andinas coloniales (siglos XVI y XVII) », in Liliana Regalado y Francisco Hernández (eds), Sobre los Incas, Instituto Riva-Agüero/Pontificia Universidad Católica, Lima, pp. 191-228.

2012 «El virrey Toledo y el control de las voces andinas coloniales », Colonial Latin American Review, 21 (2), pp. 175-208.

Martínez José Luis, Carla Díaz, Constanza Tocornal y Verónica Arévalo.

2009 «Narraciones en tensión. Un contrapunto entre algunos textos escritos y visuales en los Andes de los siglos XVI y XVII », ponencia presentada al VII Congreso chileno de antropología, ms.

Martínez S. Paula

2010 "Algunas consideraciones en torno al concepto de oralidad y su aplicación en el análisis de textos coloniales », Actas del $6^{\circ}$ Congreso de antropología chilena, tomo II, Valdivia, pp. 1970-1979.

Molina Cristóbal de

2010 Relación de las fábulas y ritos de los Incas, edición de Paloma Jiménez del Campo, Iberoamericana, Madrid/Vervuert, Frankfurt [1575].

\section{Mora Gerardo}

2010 « Notas de campo, Inacaliri », ms.

ONG Walter

1987 Oralidad y escritura. Tecnologías de la palabra, Fondo de Cultura Económica, México.

ORÉ Luis Jerónimo de

1607 Rituale seu manuale peruanum, Neapoli Jac. Carlinus.

Pachacuti Yamqui Salcamaygua Joan de Santa Cruz

1993 Relacion de antiguedades deste Reyno del Piru, estudio etnohistórico y lingüístico de Pierre Duviols y César Itier, Institut français d'études andines, Lima/Centro de estudios regionales andinos «Bartolomé de las Casas », Cuzco [1613?].

PALMiero Tiziana

2011 «Tupamaro de Caxamarca: tonadas sobre la muerte del Inca Atahualpa, contenidas en el códice Martínez Compañón (1782-85) », Revista musical chilena, 65 (216), pp. 8-33.

\section{Posnansky Arthur}

1945 Tihuanacu: la cuna del hombre americano, J. J. Augustin, Nueva York. 
Presta Ana María

2012 «Prácticas, representaciones y materialidades. La producción histórica del colonialismo tras las consumidoras indígenas. Charcas, Siglos XVI-XVII », ponencia presentada al $54^{\circ}$ Congreso internacional de americanistas, Viena, ms.

RAMOS GómEz Luis

2001 «Mama Guaco y Chañan Curi Coca: un arquetipo o dos mujeres de la historia inca (reflexiones sobre la iconografía de un cuadro del Museo de la Universidad de San Antonio Abad del Cuzco)», Revista Española de Antropología Americana, 31, pp. 165-187.

$2002 \quad$ "El choque de los incas con los chancas en la iconografía de las vasijas lígneas coloniales ", in Javier Flores Espinoza y Rafael Varón (eds), El hombre y los Andes. Homenaje a Franklin Pease G. Y., tomo II, Universidad Católica del Perú, Lima, pp. 871-885.

2006 "Aproximación a las escenas del "Inca y la coya bajo el arcoíris" de las vasijas andinas de madera de la época colonial », in Manuel Casado, Antonio Castillo, Paulina Numhauser y Emilio Sola (eds), Escrituras silenciadas en la época de Cervantes, Universidad de Alcalá, Alcalá de Henares, pp. 315-331.

2008 "La escena del "Brindis con el Sol" en los queros o vasos de madera andinos de época colonial », Revista Española de Antropología Americana, 38 (1), pp. 139-166.

Rowe John H.

1961 "The cronology of Inca wooden cups », Essays in Precolumbian art and archaeology, 22, pp. 317-341.

SALOMON Frank

1994 «La textualización de la memoria en la América andina: una perspectiva etnográfica comparada », América indígena, 54 (4), pp. 229-261.

SARmiento de Gamboa Pedro

2001 Historia de los Incas, Miraguano Ediciones/Ediciones Polifemo, Madrid [1572].

TAYLOR Gérald

1987 Ritos y tradiciones de Huarochirí. Manuscrito quechua de comienzos del siglo XVII, versión paleográfica, interpretación fonológica y traducción al castellano por Gérald Taylor, estudio biográfico sobre Francisco de Ávila de Antonio Acosta, Instituto de Estudios Peruanos/Institut français d'études andines, Lima.

2003 El sol, la luna y las estrellas no son Dios... La evangelización en quechua (siglo $X_{V I}$ ), Institut français d'études andines/Pontificia Universidad Católica del Perú, Lima.

VÁSQUEZ DE ESPINOZa Antonio

1969 Compendio y descripción de las Indias Occidentales, Eds. Atlas, col. «Biblioteca de Autores Españoles », Madrid [1630]. 
WichrowsKa Oriana y Mariusz Zı́́ŁKowsKI

2000 «Iconografía de los Keros », Andes. Boletín de la Misión arqueológica andina, 5, pp. 3-143.

Zárate Agustín de

1995 Historia del descubrimiento y conquista del Perú, edición de Franklin Pease y Teodoro Hampe, Universidad Católica del Perú, Lima [1555].

Zı́́ŁKowski Mariusz

2000 «Los keros del Museo estatal de etnografía de Varsovia », in Oriana Wichrowska y Mariusz Ziółkowski, Iconografía de los keros, Misión arqueológica andina, Universidad de Varsovia, col. « Andes» 5, Varsovia.

ZıóŁKowsKi Mariusz, Jaroslav ARABAs y Jean SzEMINSKI

2008 «La historia en los queros: apuntes acerca de la relación entre las representaciones figurativas y los signos "tocapus" ", in Paola González y Tamara Bray (eds), Lenguajes visuales de los incas, col. "British Archaeological Reports International Series 1848 », Archeopress, Oxford, pp. 163-176.

Zuidema R. Tom

1989 «El juego de los ayllus y el amaru », in Reyes y guerreros. Ensayos de cultura andina, FOMCIENCIAS, Lima, pp. 256-272 [1967, Journal de la Société des Américanistes, 56 (1), pp. 41-51]. 